Portland State University

PDXScholar

\title{
The Applicability of Microcomputers to Local Water Management
}

Roderick Lee Allen

Portland State University

Follow this and additional works at: https://pdxscholar.library.pdx.edu/open_access_etds

Part of the Civil Engineering Commons, and the Hydraulic Engineering Commons Let us know how access to this document benefits you.

Recommended Citation

Allen, Roderick Lee, "The Applicability of Microcomputers to Local Water Management" (1985).

Dissertations and Theses. Paper 3417.

https://doi.org/10.15760/etd.5296

This Thesis is brought to you for free and open access. It has been accepted for inclusion in Dissertations and Theses by an authorized administrator of PDXScholar. Please contact us if we can make this document more accessible: pdxscholar@pdx.edu. 
AN ABSTRACT OF THE THESIS OF Roderick Lee Allen for the Master of Science in Engineering: Civil presented February 20,1985 .

Title: The Applicability of Microcomputers to Local Water Management.

APPROVED BY MEMBERS OF THE THESIS COMMITTEE:

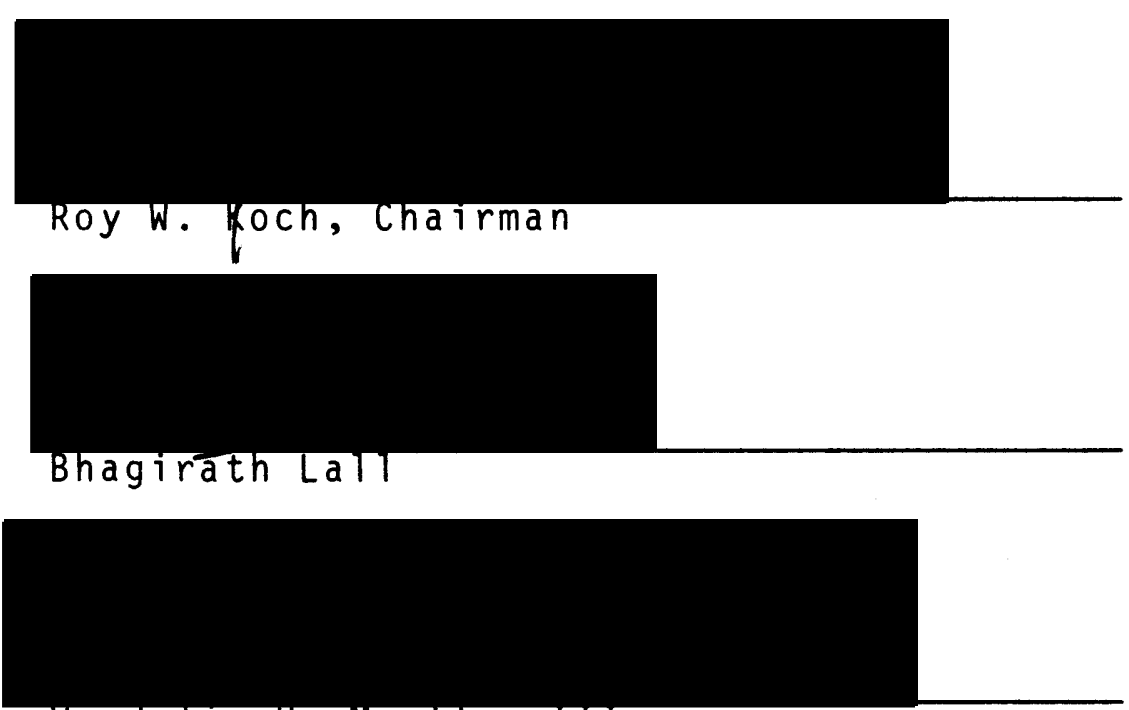

Wendelin H. Mueller III

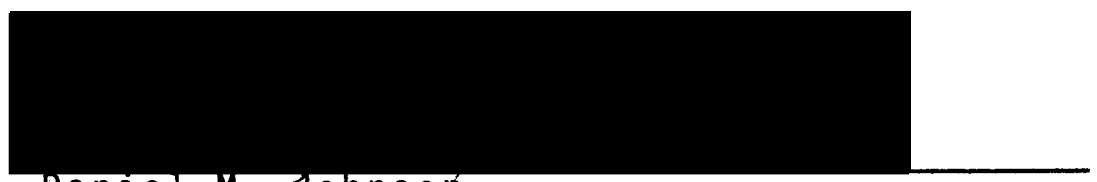

Daniel M. Johnson

Historically, hydrologic models have been available only on mainframe computers and have therefore not been used by local water managers to support daily decisions. The 
development of the microcomputer presents an opportunity for that to change.

Mathematical models of soil moisture and river routing are selected, developed and tested for use on a microcomputer as an aid to local water management. The models are then integrated with an appropriate data base in a computer program written for a microcomputer. The result is a Decision Support System for local water managers. In order to evaluate the feasibility of using the Decision Support System, an application of the program to a small hypothetical river and irrigation system is carried out. The speed of execution indicates that the use of the Decision Support System on this class of computer under the present configuration may be possible if software or hardware changes can reduce data transfer times to and from disk. 


\title{
THE APPLICABILITY OF MICROCOMPUTERS \\ TO LOCAL WATER MANAGEMENT
}

\author{
by \\ RODERICK LEE ALLEN
}

A thesis submitted in partial fulfillment of the requirements for the degree of

\author{
MASTER OF SCIENCE \\ in \\ ENGINEERING：CIVIL
}

Portland State University 1985 
TO THE OFFICE OF GRADUATE STUDIES AND RESEARCH:

The members of the Committee approve the thesis of Roderick Lee Allen presented February 20, 1985.

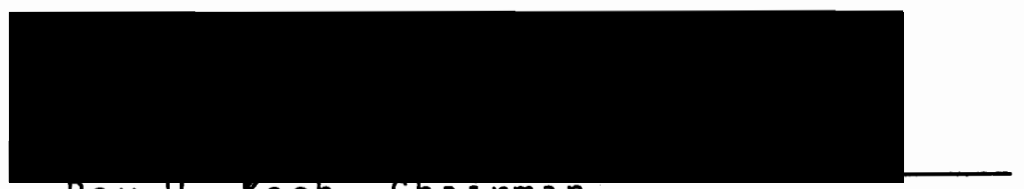

Roy W. Foch, Chairman

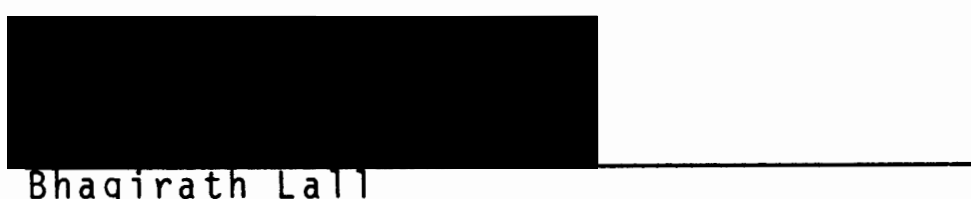

Bhagirath Lall

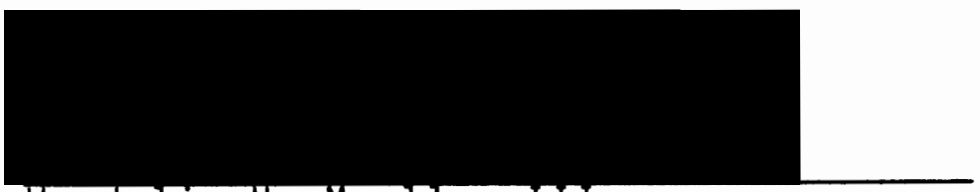

Wendelin H. Muether III

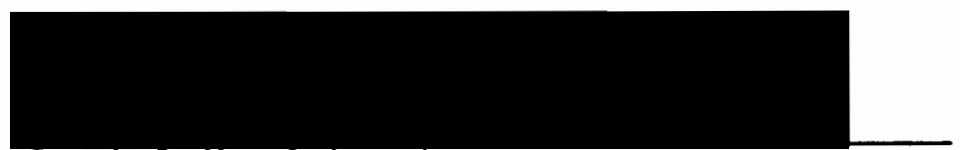

Daniel M. Johnson

APPROVED :

Fyanz N. Rad, Head, Department of Civil Engineering

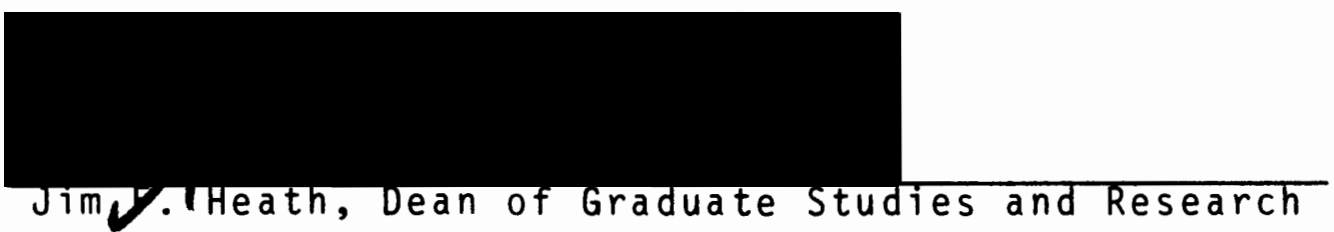




\section{ACKNOWLEDGEMENTS}

I would like to thank Dr. Roy W. Koch for providing guidance, assistance, and insight which was essential to the work presented here. This thesis relies heavily on his ideas.

I am greatly appreciative of my wife Taya for her support, understanding and patience while she waited for me to finish.

I am indebted to Greg Jones and Dan Clark for their assistance with some of the programming.

I would like to thank the Oregon Water Resources Research Institute for providing funding for this project. I would also like to thank the Department of Civil Engineering of Portland State University for support in the form of a graduate assistantship.

Palmer Torvend of the Tualatin Valley Irrigation District and Monte McVay of the United States Bureau of Reclamation were very helpful in providing data and comments. I would like to thank them for their assistance.

Finally, I owe a big thank you to my family and to friends too numerous to mention here for support and encouragement which they have given during the entire time I have been in school. 
TABLE OF CONTENTS

PAGE

ACKNOWLEDGEMENTS .

i i i

LIST OF TABLES . • . . . . . . . . . . . . . . . . . vi

LIST OF FIGURES . . . . . . . . . . . . . . . . . . . v vi

LIST OF SYMBOLS . . . . . . . . . . . . . . . . . $x$

CHAPTER

I INTRODUCTION . . . . . . . . . . . . . 1

The Research Strategy. . . . . . . 3

I I COMPONENT MODELS . . . . . . . . . . . . 5

Soil Moisture............. 6

Redistribution and Drainage

Evapotranspiration

Flow Routing . . . . . . . . . .

Fundamental Equations

The Linear Reservoir

A Cascade of Linear Reserviors

State Space

Evaluation

Return Flow............. 
III THE DATA BASE . . . . . . . . . . . . 54

Data Requirements for Water Management . 54

Specific Data Requirements . . . . . 55

Water Use Data

Hydrologic Data

Flow Routing Data

Crop and Soil Parameters

Miscellaneous Information

Sources of Data........... . 60

IV THE DECISION SUPPORT SYSTEM . . . . . . . 63

Programming Philosophy . . . . . . 63

Program organization ........ 65

File Editing Routines

The Workfile Builder

System Simulator

Program Operation........ . . 75

V AN APPLICATION . . . . . . . . . . 76

VI CONCLUSIONS, SUMMARY, AND RECOMMENDATIONS • 91

Summary............ . . 92

Recommendations.......... 94

REFERENCES . . . . . . . . . . . . . . . . 97 


\section{LIST OF TABLES}

TABLE

PAGE

I Calibration results . . . . . . . . .

I Soil parameters for sandy loam, loam, and clay loam................ 22

II The matrix of influences. . . . . . . . 43

IV Physical parameters and resulting reach

lengths for the linear reservoir model. .

$\checkmark$ Reach lengths and routing constants used in

the Tualatin River simulation . . . . 50

VI Data stored for each water use in the system . . . . . . . . . . 56

VII Entries in the water right workfile . . . . 72

VIII Water right data............ . 80

IX The climatological data file........ 81

X Soil parameter file . . . . . . . . . . 81

XI Crop parameter file . . . . . . . . . 82

XII The flow file . . . . . . . . . . 83 


\section{LIST OF FIGURES}

FIGURE

PAGE

2.1 A schematic representation of a portion of the hydrologic cycle............. . . 7

2.2 Definition sketch of soil moisture terms . . . 8

2.3 The sharp wetting front approximation .... 11

2.4 Behavior of the sharp wetting front during

redistribution and drainage. Numbers

indicate successive profiles . . . . 12

2.5 The linear approximation of unsaturated

hydraulic conductivity. . . . . . . . . 14

2.6 Initial and final root zone depth

assumptions . . . . . . . . . . . . 18

2.7 Comparison of simulated and observed sand

flume drainage data . . . . . . . . 21

2.8 Comparison of daily drainage volumes obtained

with and without modelling redistribution.

Application depth is 1.2 centimeters.. . 24

2.9 The piecewise linear evapotranspiration approximation . . . . . . . . . 26

2.10 Simulation of Tualatin Valley Irrigation

District soil moisture data for pasture.

Root zone depth varied as indicated ... 
viii

F I GURE

PAGE

2.11 Simulation of Tualatin Valley Irrigation

District soil moisture data for

strawberries. Crop coefficient varied

during the season as indicated......

28

2.12 Simulation of Tualatin Valley Irrigation

District soil moisture data for corn.

Cover occurs $8 / 1 / 79$, and crop coefficient

varies as indicated during the season .

2.13 A four reach river system . . . . . . . . 38

2.14 Map of the Tualatin River study area. Numbers indicate river reach . . . . . . . . .

2.15 Comparison of measured and modelled discharge

of the Tualatin River . . . . . . . 53

4.1 Overall program organization . . . . . . 66

4.2 Organization of the file-editing routines . . 67

4.3 A typical page of input prompts . . . . . . 69

4.4 Organization of subroutine BWF . . . . . . . . 71

4.5 Organization of subroutine SMMAIN $\quad . \quad . \quad . \quad . \quad . \quad 74$

5.1 The main menu . . . . . . . . . . . 77

5.2 The hypothetical system . . . . . . . . 78

5.3 The displaymenu. . . . . . . . . . . . . 84

5.4 The reports of modelled conditions . . . . . 86

5.5 Modelled conditions after the second

iteration . . . . . . . . . . . 87 


\section{LIST OF SYMBOLS}

SYMBOL

DEFINITION

A Cross-sectional area of flow.

A Coefficient matrix in state space notation.

B Channel width.

B Coefficient matrix in state space notation.

c Celerity, or speed of a flow disturbance.

C Chezy coefficient.

D Depth of the root zone.

$d_{n} \quad$ Element in the state transition matrix.

d/dt Derivative (rate of change) with respect to time.

ET Potential evapotranspiration reduced by the crop consumptive use factor.

ET $_{p} \quad$ Potential evapotranspiration.

exp Natural exponential function.

F Cumulative infiltration depth due to an irrigation or precipitation.

fe Lateral outflow per unit length and width of channel.

g Gravitational acceleration.

G Rate of drainage from the root zone caused by gravity.

$h_{c}$ Head across the wetting front due to capillarity.

I Rate of input to a control volume or flow routing reach.

I Identity matrix. 
Ic Constant input to a linear routing reach.

$I_{n} \quad$ Inflow to the $n^{\text {th }}$ routing reach.

IUH $_{n}$ Instantaneous unit hydrograph for a cascade of $n$ unequal linear reservoirs.

j An index.

$k$ Parameter in the Muskingum routing equation which, after simplification, becomes the routing constant in the linear reservoir equation. Also an index.

K Conveyance.

K Crop consumptive use factor which is applied to potential evapotranspiration to account for stage of growth.

$\mathrm{K}_{\mathrm{e}} \quad$ Effective saturated hydraulic conductivity according to the linear approximation.

$k_{n} \quad$ Routing constant for the $n^{\text {th }}$ routing reach.

$\mathrm{K}_{\mathrm{S}} \quad$ Hydraulic conductivity at natural saturation.

$K(\theta)$ Unsaturated hydraulic conductivity as a function of soil moisture.

n Exponent which provides the best power curve approximation of relative hydraulic conductivity as a function of soil moisture. Also an index.

N The matrix of influences.

Q Rate of flow, or discharge.

$Q(t)$ Vector containing the discharge of each routing reach.

qe Lateral inflow per unit length and width of channel.

$q_{1} \quad$ Lateral inflow per unit length of channel.

$Q_{n} \quad$ Discharge from the $n^{\text {th }}$ routing reach.

$Q_{0} \quad$ Initial flowrate in a linear routing reach. 
$\underline{r}(t)$ Vector containing the inputs or forcing function in state space notation.

R Hydraulic radius.

$\mathrm{R}_{\mathrm{S}}$ Solar radiation.

s Transform variable.

$S$ Storage in a control volume or flow routing reach.

$S_{f} \quad$ Friction slope.

So Bed slope.

$S_{n}$ Storage in the $n^{\text {th }}$ routing reach.

$S_{1}$ Storage in a control volume or flow routing reach.

$t$ Time. Also a routing period.

$T$ Average daily temperature.

$v \quad$ Last index in the series $i, j, k, \ldots, v$.

$\checkmark \quad V e l o c i t y$ of flow.

$x$ Flow direction axis. Also a parameter in the Muskingum flow routing equation.

$y \quad$ Local depth of flow.

$z$ Depth below soil surface.

$z_{\text {w }}$ Depth of the sharp wetting front.

$z_{0} \quad$ Initial depth of the sharp wetting front after input stops.

$\alpha \quad$ An index.

B An index.

$\gamma \quad$ An index.

a/at Partial derivative with respect to time.

a/ax Partial derivative with respect to location. 
$\partial^{2} / \partial x^{2}$ second partial derivative with respect to location. $\Delta x \quad$ Routing reach length.

$\theta \quad$ Volumetric water content, or soil moisture.

${ }^{\theta}$ fc Soil moisture at the field capacity.

$\theta_{i} \quad$ Initial uniform soil moisture before input starts.

${ }^{\theta} s$ Soil moisture at natural saturation.

$\theta_{w}$ Soil moisture at the wilting point.

$\theta_{0} \quad$ Limiting soil moisture during input.

$\theta$ * Non-dimensional soil moisture ranging from zero at the field capacity to one at natural saturation.

$\theta_{i}^{*} \quad$ Non-dimensional value of the initial uniform soil moisture.

$\theta_{0}^{*} \quad$ Non-dimensional value of the limiting soil moisture.

$\mathscr{L}^{-1} \quad$ Inverse Laplace Transform.

$\triangle$ Convolution matrix.

II Product.

$\Sigma$ Summation.

$\int d \tau$ Integration with respect to $\tau$.

$\tau$ Dummy variable of integration in the convolution integral.

$\Phi \quad$ State transition matrix. 


\section{CHAPTER I}

\section{INTRODUCTION}

Dry times such as the summer of 1976 in the Pacific Northwest emphasize the importance of an adequate supply of water. With increasing agricultural, municipal, and industrial demands, and with the better recognition of the water requirements of wildlife, shortages will occur more frequently, so methods which improve the water supply will receive increasing attention.

One traditional method for increasing the quantity of available water during shortages is to save it during times of abundance by building dams. This has worked well before, but an increased awareness of the environmental problems associated with dams, a dwindling number of suitable dam sites, and possibly the most important, a shift from large scale federal financing have severely limited the current feasibility of dam construction.

An alternative technique which can be used when it is not possible to increase the supply of a limited resource is to reduce demand for that resource by increasing the efficiency with which it is used. Improved efficiency is often the result of the better understanding of a natural system which is obtained through the construction and use of 
a mathematical model of the system. In the case of water supply, a mathematical model of the pertinent components of the hydrologic cycle can be used by a person involved with the management of water resources as a tool to evaluate management decisions, so that decisions which maximize water use result.

The level of management to be addressed in this thesis is management on a local scale, such as by a state water master or the manager of an irrigation district. The type of water use emphasized is irrigation, so the modelled components of the hydrologic cycle are the behavior of water in the soil in irrigated fields and the flow of water in rivers.

Mathematical models which describe soil moisture in irrigated fields and the response of a river to water diversions have already been written, but they have typically been available only to managers with access to expensive mainframe computer installations. Even then, operation of the appropriate computer software has been too time consuming to permit evaluation of the impact of daily management decisions. Estimates have therefore been based on experience. Although the local water manager typically knows his or her area thoroughly and can make reasonable estimates of the effects of various diversions, increased demand makes rough, experience-based estimates inappropriate. 
What is proposed, therefore, is a Decision Support System (DSS) which may be used by a local water manager as a tool to estimate the effects of various water-distribution schemes by modelling them mathematically. The DSS is used to keep track of current conditions so that it can provide short-term estimates of water demand which are to be used in the modelled results of a management decision. Rather than writing the DSS for use in a large computer installation, it is written for a microcomputer. The microcomputer's abilities to do bookkeeping and word processing have resulted in its presence in the offices of many local water managers already, so a program written for use on a microcomputer is more likely to actually be used than one written for a mainframe computer. The development and evaluation of DSS software written for an Apple IIe personal computer is presented in this thesis.

\section{THE RESEARCH STRATEGY}

The Decision Support System requires mathematical models of soil moisture and flow routing. Many models which adequately describe those processes are available in the literature, so the first phase of development of the DSS is the selection of models of those component processes. Since calibration is time and data intensive, selected models have parameters which are measurable characteristics of the physical system being modelled. 
Once component models are selected, it is desirable to simplify them if possible in order to reduce their computational time requirements. Only those simplifications which do not result in significant losses of accuracy in modelled results are permitted. The validity of simplified models is checked by testing them with measured data.

The creation of a suitable data base depends on the data requirements of the resulting component models. The final phase of development of the DSS, then, is the integration of the simplified component models with an appropriate data base in software written for the Apple Ile. The interaction of the component models and data base is then tested. 


\section{CHAPTER II}

\section{COMPONENT MODELS}

Water in its various forms circulates in a natural cycle called the hydrologic cycle (Linsley, Kohler, and Paulhus, 1982) which is the source of fundamental mass conservation concepts. These form the basis of most models of hydrologic processes. Rather than accounting for water in every phase of the hydrologic cycle, certain essential components are selected for modelling in order to obtain desired results without wasted effort. Components of the hydrologic cycle which need to be modelled to aid in local water management are soil moisture in irrigated fields, flow in the river in the area subject to regulation, diversions and applications of water for irrigation or other uses, and return flow due to the slow seepage of excess soil moisture into the groundwater table and eventually into the river. Precipitation on irrigated fields and all flow entering the regulated portion of the river including tributary inflows as well as the main river inflow are components of the hydrologic cycle which are accounted for in this model by user input rather than by computer simulation. The soil moisture component of the hydrologic cycle is affected by the evaporation of water from the soil surface and the 


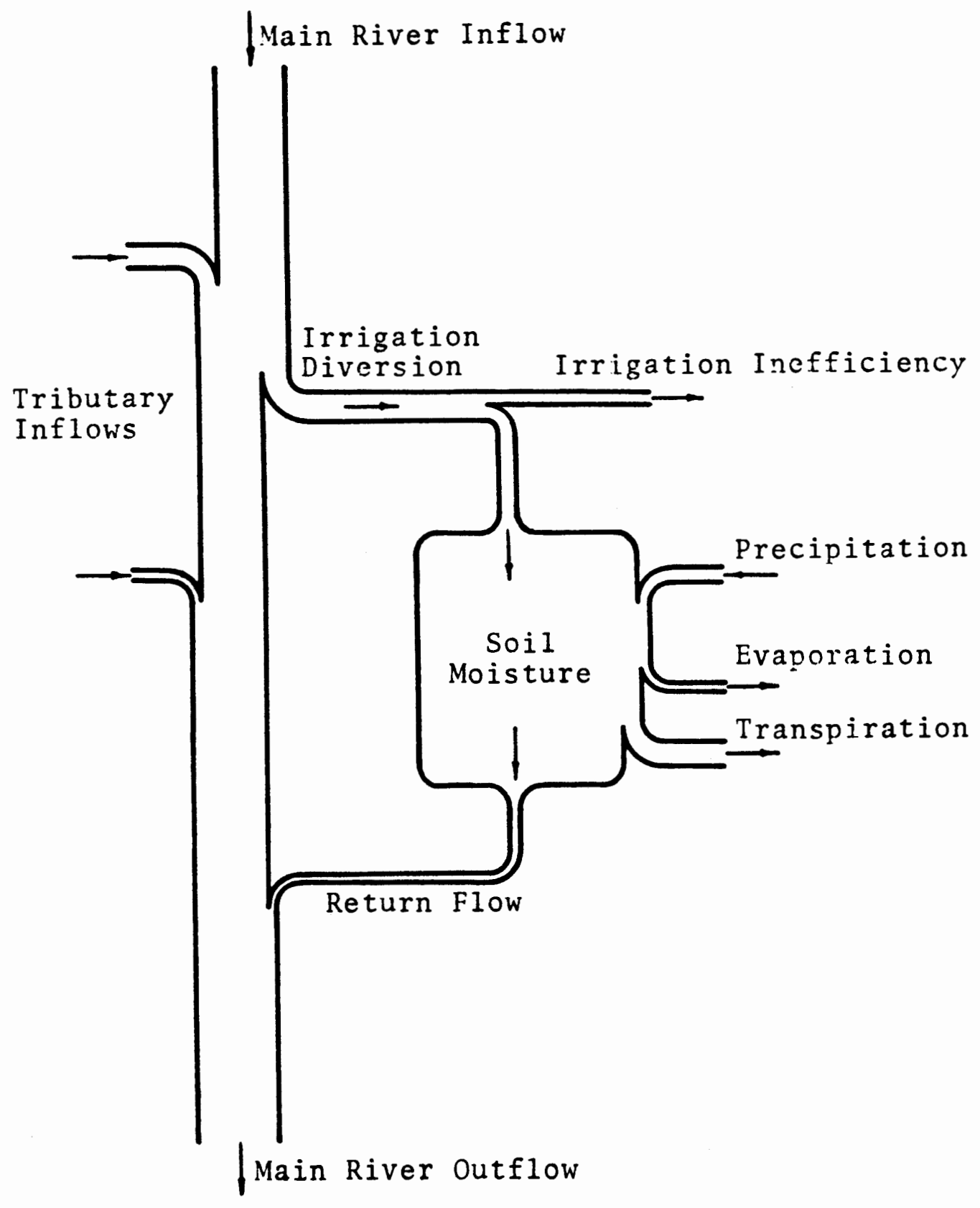

Figure 2.1 A schematic representation of a portion of the hydrologic cycle. 


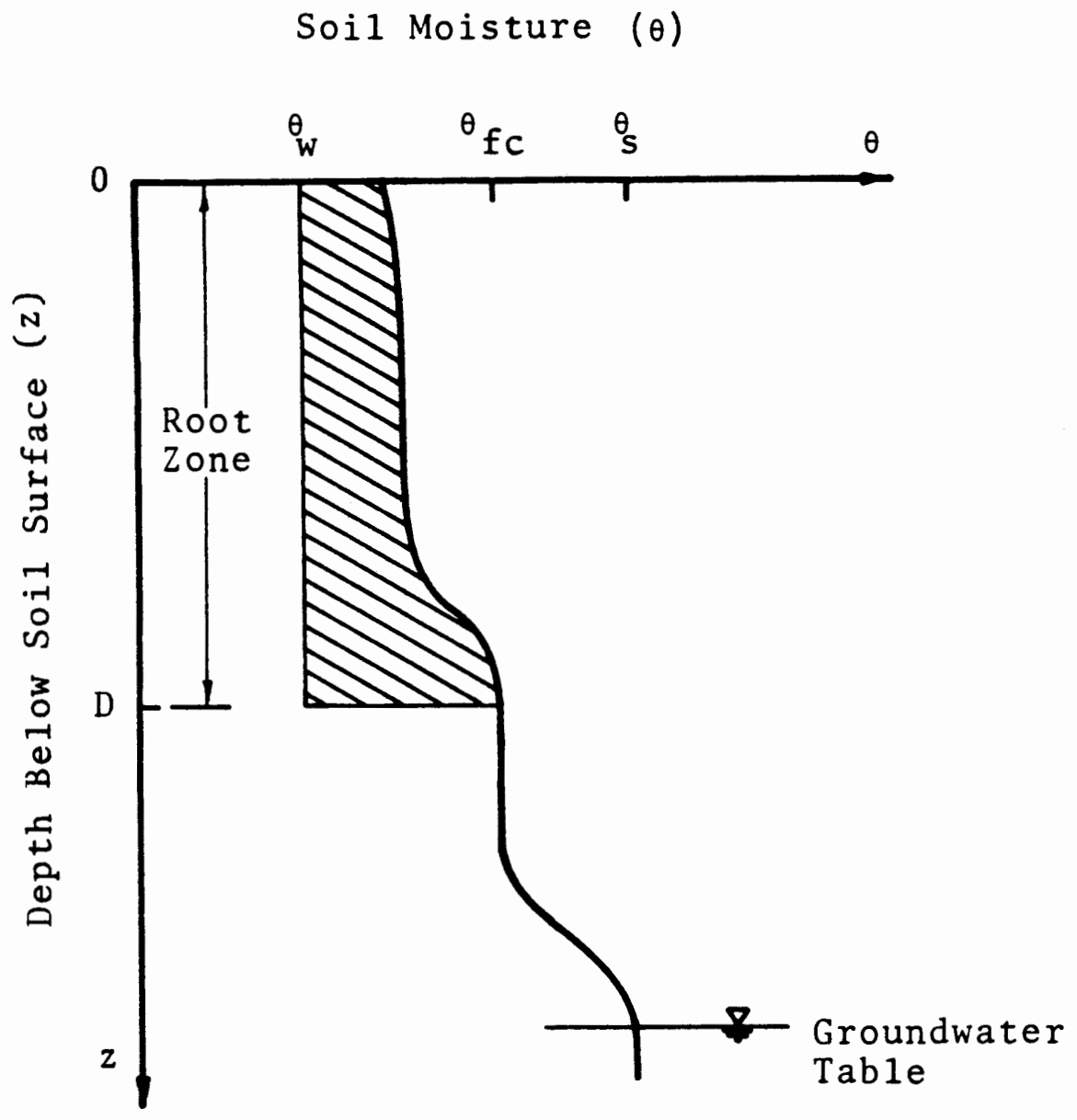

Figure 2.2 Definition sketch of soil moisture terms. 
water. The shaded region shown in figure 2.2 represents soil moisture which is available to plants. Available water (AW) is the difference between the field capacity and the wilting point of a soil. The sketch shows a particular soil moisture profile which has a soil moisture deficit created by evapotranspiration and represented by the area in the root zone between the soil moisture profile and the field capacity. An additional feature of the soil moisture profile which is important is the region near the groundwater table which has a soil moisture greater than the field capacity due to capillary rise from the groundwater table.

Soil moisture is modelled in phases. It is necessary to model the redistribution and drainage of moisture entering the root zone as the result of an irrigation or storm in order to correctly estimate the timing of recharge to the groundwater table and hence the timing of return flow to the river. Also, the slower decline in soil moisture caused by evapotranspiration is modelled to estimate soil moisture between irrigations or storms so that demand for irrigation water may be anticipated.

Redistribution and Drainage

In order to simplify the modelling of soil moisture redistribution in the root zone, the actual shape of the soil moisture profile and wetting zone are approximated as 
shown in figure 2.3 (e.g. Mein and Larson, 1973) which represents a vertical line in the soil profile. For a constant rate of infiltration (irrigation or rainfall), the assumption of gravity dominated drainage results in the soil nearest the surface obtaining a value of soil moisture at which the relative hydraulic conductivity equals the ratio of input rate to the saturated hydraulic conductivity (Bazarra, 1979), referred to as the limiting soil moisture, $\theta_{0}$. The limiting soil moisture is calculated using:

$$
\begin{aligned}
& \theta_{0}=\theta_{f c}+\left(\theta_{s}-\theta_{f c}\right)\left(I / K_{s}\right)(1 / n) \\
& \text { rate of input (length/time), } K_{s} \text { is the }
\end{aligned}
$$
hydraulic conductivity at natural saturation, and $n$ is the exponent which provides the best power curve approximation of relative hydraulic conductivity as a function of soil moisture when compared to measured data (see figure 2.5 and accompanying discussion). The wetting front advances creating a zone near the surface at the limiting soil moisture throughout the duration of the input. Once the input stops, the rectangular wetting zone is assumed to change shape as shown by profiles 1 through 5 in figure 2.4. Drainage from the root zone occurs during the change from profile 4 to profile 5. In order to track the wetting zone during the progression from profile 1 to the time moisture reaches the bottom of the root zone (profile 4), consider a mass balance written for the wetting zone:

$$
d S / d t=I-G
$$


11

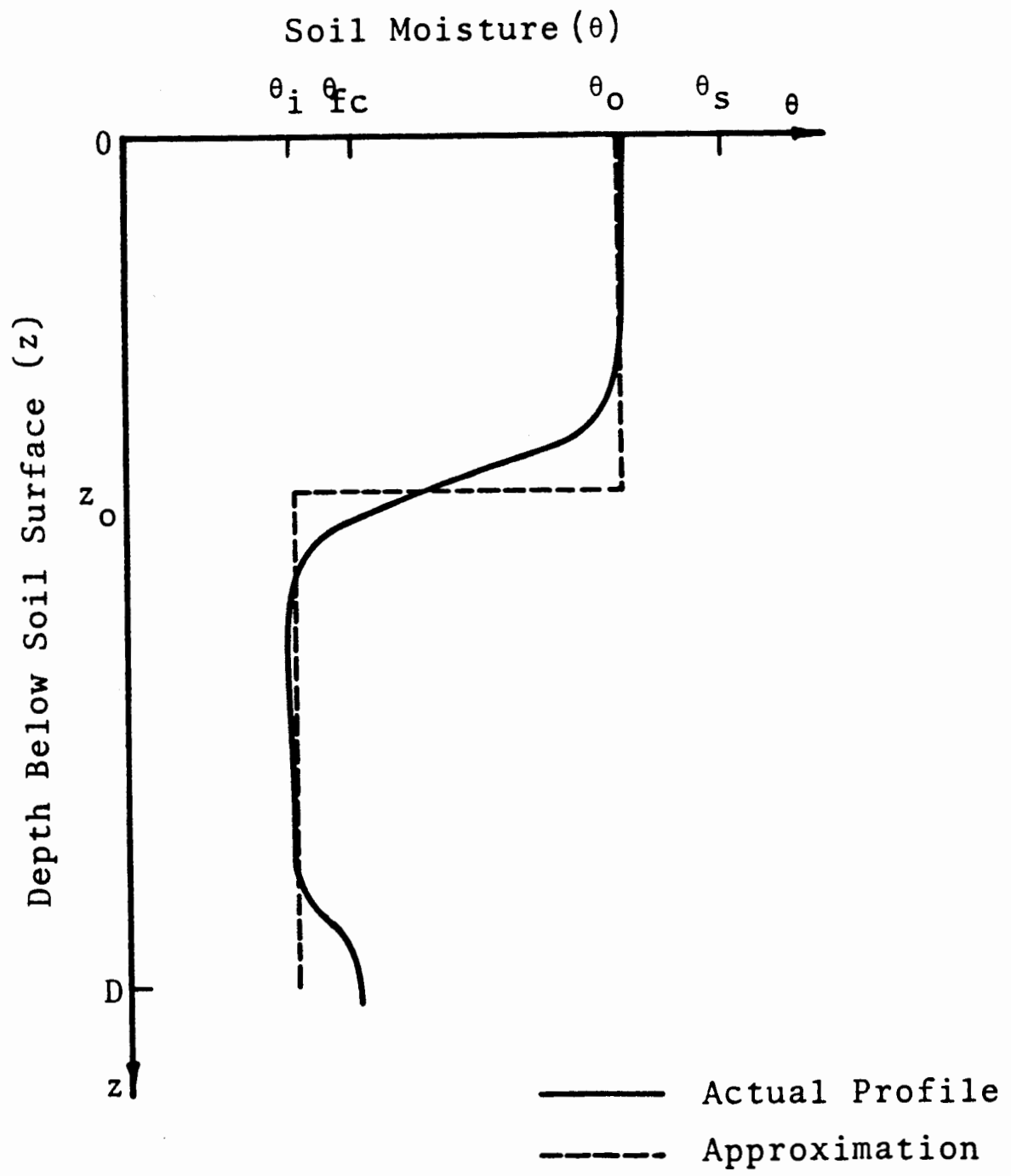

Figure 2.3 The sharp wetting front approximation. 


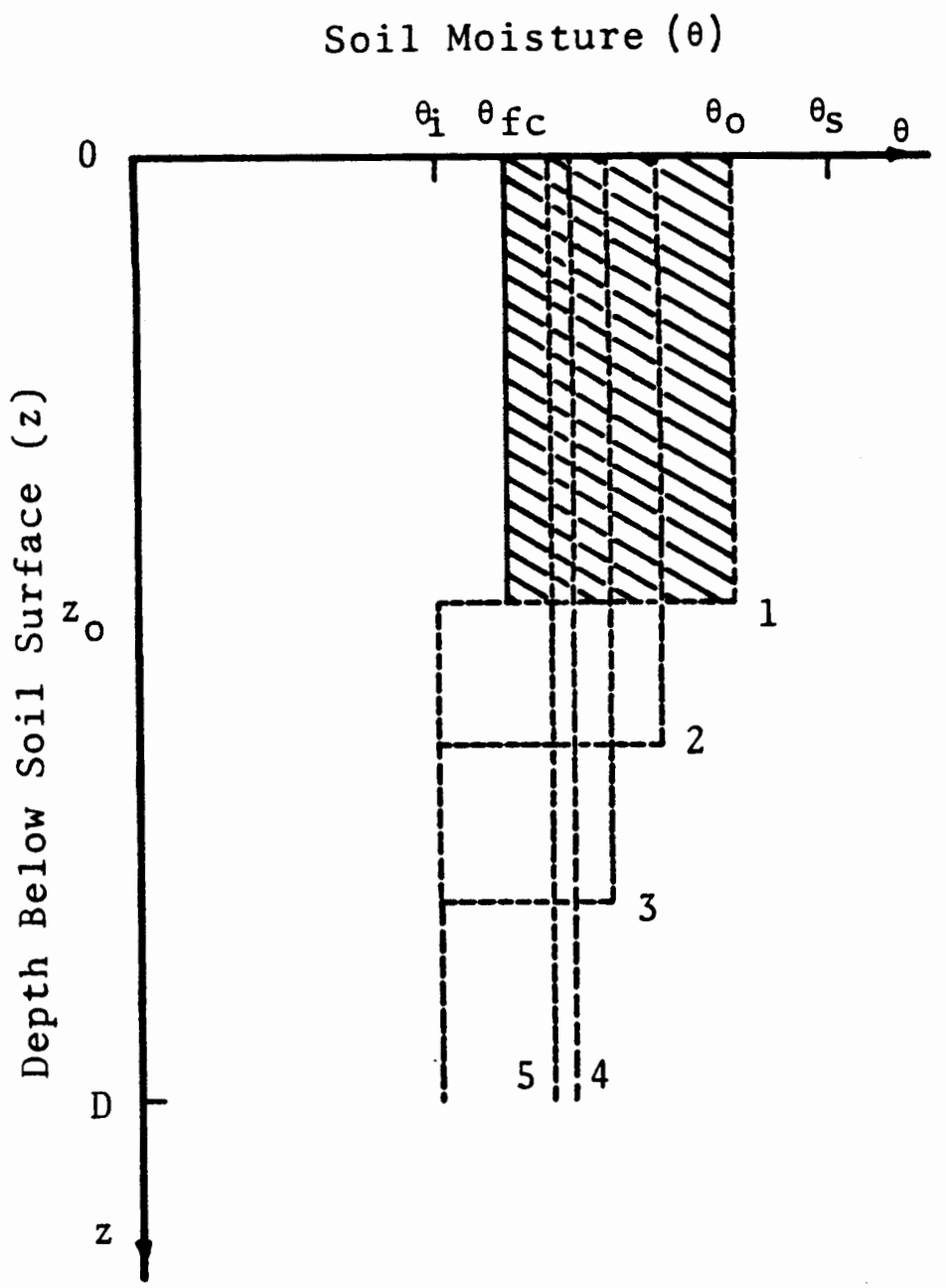

Figure 2.4 Behavior of the sharp wetting front during redistribution and drainage. Numbers indicate successive profiles. 
In this equation, $S$ is the quantity of water contained in the control volume shown shaded in figure 2.4 , $t$ is time (taken to be zero when profile 1 occurs), I is the rate of input which is zero, and $G$ is the rate at which gravity causes drainage through the bottom of the control volume. Evapotranspiration is neglected since the redistribution process happens relatively rapidly.

In order to solve the differential Eq. 2.2, some expression for $G$ must be used. The actual drainage will be caused by gravity and capillarity and can be obtained using Darcy's Law written across the wetting zone:

$$
G=K(\theta)\left(z_{w}+h_{C}\right) / z_{w}
$$

where $z_{w}$ is the depth of the wetting front, $h_{c}$ is the head across the wetting front due to capillarity, and $K(\theta)$ is the hydraulic conductivity at the soil moisture in the wetting zone. If $h_{c}$ is assumed negligible in comparison to $z_{w}$ and $K(\theta)$ is linearized as shown in figure 2.5 , the drainage rate is equal to the hydraulic conductivity.

It is also necessary to eliminate the variable $S$ by the relation:

$$
S=\left(\theta-\theta_{f c}\right)\left(z_{o}\right)
$$

where $z_{0}$ is the initial depth of the wetting front, represented by the distance from the soil surface to the bottom of the shaded region in figure 2.4 .

Inserting $K(\theta)$ for $G$ in Eq. 2.2, eliminating $S$, and solving for soil moisture as a function of time gives: 

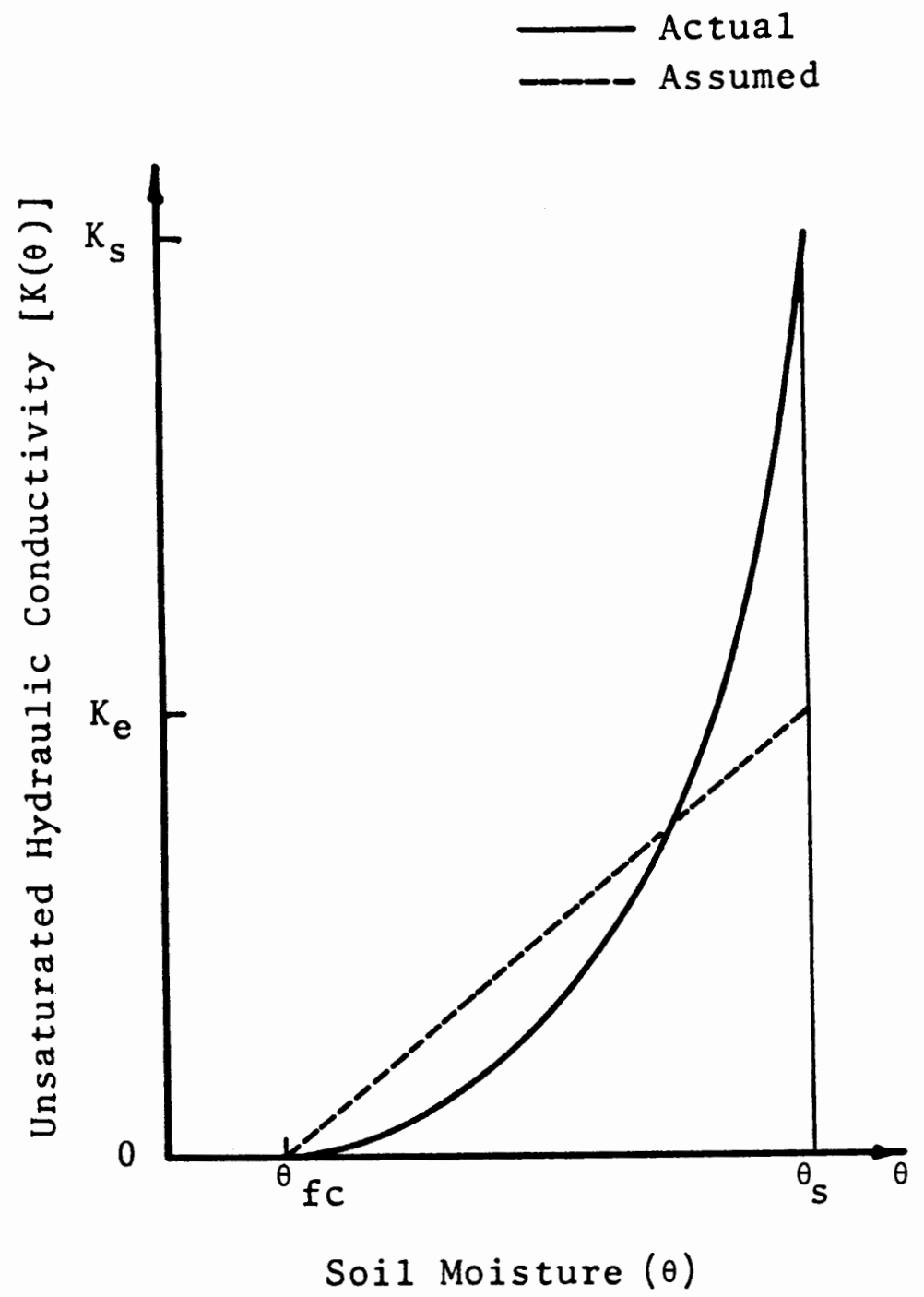

Figure 2.5 The linear approximation of unsaturated hydraulic conductivity. 


$$
\theta^{*}(t)=\theta_{0} * \exp \left(-\left(K_{e} / F\right)\left(\theta_{0}^{*}-\theta_{i}^{*}\right) t\right)
$$

where $\theta^{*}$ is a non-dimensional soil moisture given by:

$$
\theta *=\left(\theta-\theta_{f c}\right) /\left(\theta_{s}-\theta_{f c}\right)
$$

$F$ is the cumulative infiltration, $\theta_{0}$ * is the non-dimensionalized value of the limiting soil moisture $\theta_{0}$, and $K_{e}$ is the maximum hydraulic conductivity according to the linearization shown in figure 2.5. This is a simple exponential decay. Using the soil moisture given by Eq. 2.5 and the known total infiltration volume $F$, the position of the wetting zone can be calculated at any time as:

$$
z_{w}=F /\left(\theta-\theta_{i}\right)
$$

where $z_{w}$ is the depth of the wetting front below the soil surface and $\theta$ is calculated from the known $\theta$ * using Eq. 2.6. Once the wetting front reaches the bottom of the root zone, $z_{w}$ equals $D$, the redistribution model presented above is no longer valid since evapotranspiration can no longer be neglected. A revision is required to track the decrease in soil moisture caused by a combination of drainage and evapotranspiration from the time profile 4 occurs (figure 2.4) until the soil moisture reaches the field capacity. At that point, drainage ceases and a third phase of the model which accounts for declines in soil moisture due to evapotranspiration only, discussed in the evapotranspiration section of this chapter, is used.

For the case when drainage and evapotranspiration are both occuring, Eq. 2.2 can be re-written as: 


$$
\mathrm{dS}_{1} / \mathrm{dt}=\mathrm{I}-\mathrm{G}-\mathrm{ET}
$$

where $S_{1}$ is the region in figure 2.4 in the root zone between the field capacity and profile 4 , I is still zero, $G$ is once again approximated as the linearized hydraulic conductivity, and ET is the potential evapotranspiration rate for a reference crop reduced by an appropriate crop consumptive-use factor, $\mathrm{K}_{\mathrm{c}}$ :

$$
E T=K_{c} E T p
$$

where $E T_{p}$ is potential evapotranspiration.

Using the relation:

$$
S_{1}=D\left(\theta-\theta_{f c}\right)
$$

and solving Eq. 2.8 for $\theta$ as a function of time gives:

$$
\theta^{*}(t)=\left(E T / K_{e}+\theta_{o}{ }^{*}\right)\left(\exp \left(-K_{e} t /\left(D\left(\theta_{s}-\theta_{f C}\right)\right)\right)\right)-E T / K_{e} 2.11
$$

where $\theta_{0} *$ is the initial non-dimensionalized soil moisture of profile 4 and other variables are the same as defined above. Once again, this is a simple exponential decay.

To evaluate the redistribution and drainage models, laboratory data on the recharge rates to a groundwater table occuring in sand as measured by Bazarra (1979) was simulated using the expressions presented above. This evaluation did not test the evapotranspiration component of the model since there were no plants in the sand flume, so the discussion of the selection of an expression for calculating potential evapotranspiration is in the next portion of this chapter. It was unclear at first how to select $K_{e}$, the effective 
saturated hydraulic conductivity shown in figure 2.5 , and $D$, the root zone depth. As a first attempt, $K_{e}$ was selected to make the area under the linear hydraulic conductivity graph equal the area under the actual hydraulic conductivity graph:

$$
\mathrm{K}_{\mathrm{e}}=\mathrm{K}_{\mathrm{s}}(2 /(n+1))
$$

where all terms are defined above, and $D$ was set at a point at which the zone of capillarity measured by Bazara could be squared off to obtain the same total volume of stored water in the zone affected by capillary rise as Bazaraa measured, shown in figure 2.6 .

An extensive calibration using Rosenbrock's method (Rosenbrock, 1960) was performed on all six parameters of this phase of the model to determine if their physical basis was reasonable. Table I presents the initial parameter set, calibrated parameter sets, and values of the calibration objective function for various calibration runs. The objective function for the calibration was the minimization of the sum of squared deviations of modelled results from measured results for 22 measurements during the first 150 minutes of Bazara's experimental run.

The parameter set resulting from a calibration of all six parameters, starting from the initial values shown is given as Run $A$. The objective function had improved considerably, but it was at the expense of physically 
Soil Moisture $(\theta)$

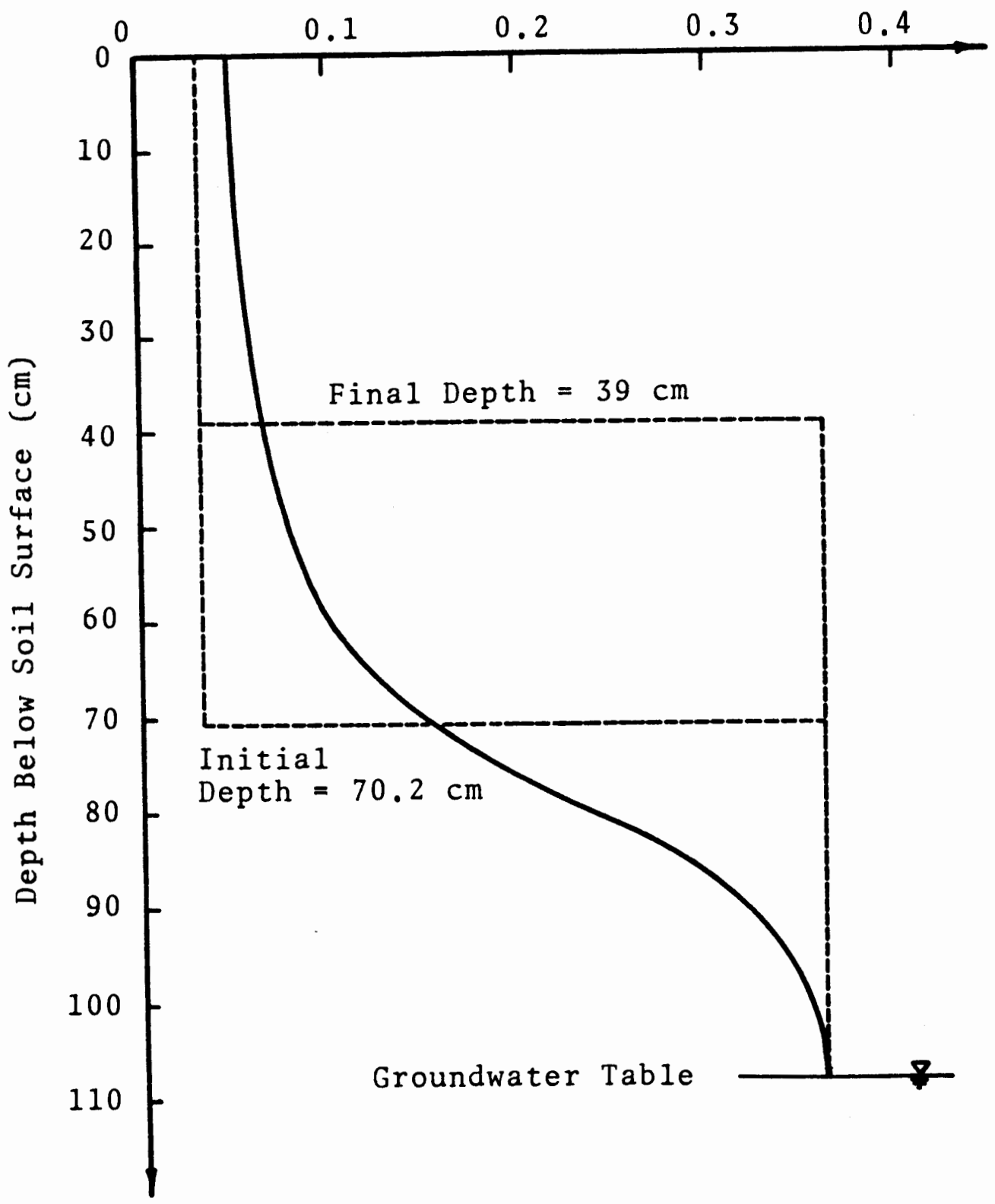

Figure 2.6 Initial and final root zone depth assumptions. 
TABLE I

CALIBRATION RESULTS

\begin{tabular}{|c|c|c|c|c|c|}
\hline Parameter & $\begin{array}{l}\text { Initial } \\
\text { Value }\end{array}$ & $\underset{A}{R u n}$ & $\underset{B}{\operatorname{Run}}$ & $\underset{C}{R u n}$ & $\begin{array}{l}\text { A-Priori } \\
\text { Selection }\end{array}$ \\
\hline$D(\mathrm{~cm})$ & 70 & 71.0 & 39.1 & 39.1 & 39 \\
\hline$K_{e}(c m / h r)$ & 25 & 25.0 & 25.3 & 25.2 & 25 \\
\hline${ }^{\theta} f_{c}(i n / i n)$ & .034 & .234 & .034 & .035 & .034 \\
\hline$\theta_{s}(i n / i n)$ & .358 & .408 & .358 & .358 & .358 \\
\hline$K_{s}(c m / h r)$ & 61.5 & 61.6 & 61.5 & 61.3 & 61.5 \\
\hline$n$ & 4 & 4.65 & 4 & 4.04 & 4 \\
\hline $\begin{array}{l}\text { 0bjective } \\
\text { Function }\end{array}$ & 944 & 61.6 & 61.5 & 61.5 & 61.9 \\
\hline
\end{tabular}

reasonable values for several of the parameters. Since $D$ and $\mathrm{K}_{e}$ were the two parameters with the poorest physical basis, a calibration run was done in which only those two parameters were allowed to vary. The result, shown as Run $B$, has a value of the objective function nearly as good as in Run $A$, but the physical basis of the other 4 parameters is maintained. The improvement was obtained by reducing $D$, with only a slight change in $\mathrm{K}_{e}$. A final calibration was performed in which all six parameters were permitted to vary, but the initial values were the results of Run $B$. The final values, shown as Run $C$, were no better than had been obtained in Run B.

These calibrations indicated that the original method for selecting $K_{e}$ was reasonable, but that better results 
were obtained with $D$ set near the top of the zone of capillary influences as shown in figure 2.6. For comparison, the value of the objective function obtained with $D$ reset to 39 centimeters, as it might have been if the capillary zone had been avoided, and with the rest of the parameters set at their initial values is shown in the last column of Table I. The objective function value obtained with this nearly a-priori selection of the parameters is only slightly larger than the best value obtained by calibration.

A comparison of measured data and model results obtained using the original $\mathrm{K}_{e}$ and the reset $\mathrm{D}$ are shown in figure 2.7. The difference in volumes of drainage shown there is accounted for by a higher ending soil moisture in the physical system than in the model. It is expected that results as good as those obtained in this simulation can be obtained in practice without calibration of any of the parameters of the model, since the groundwater table is usually sufficiently below the root zone to prevent interference and a suitable method for calculating $\mathrm{K}_{\mathrm{e}}$ based on physical parameters is known. All other parameters are selected based on reported values.

The discrepancy created between actual maximum hydraulic conductivity, $K_{s}$, and modelled maximum hydraulic conductivity, $\mathrm{K}_{e}$, by the linearization of hydraulic conductivity shown in figure 2.5 is not a problem in this 


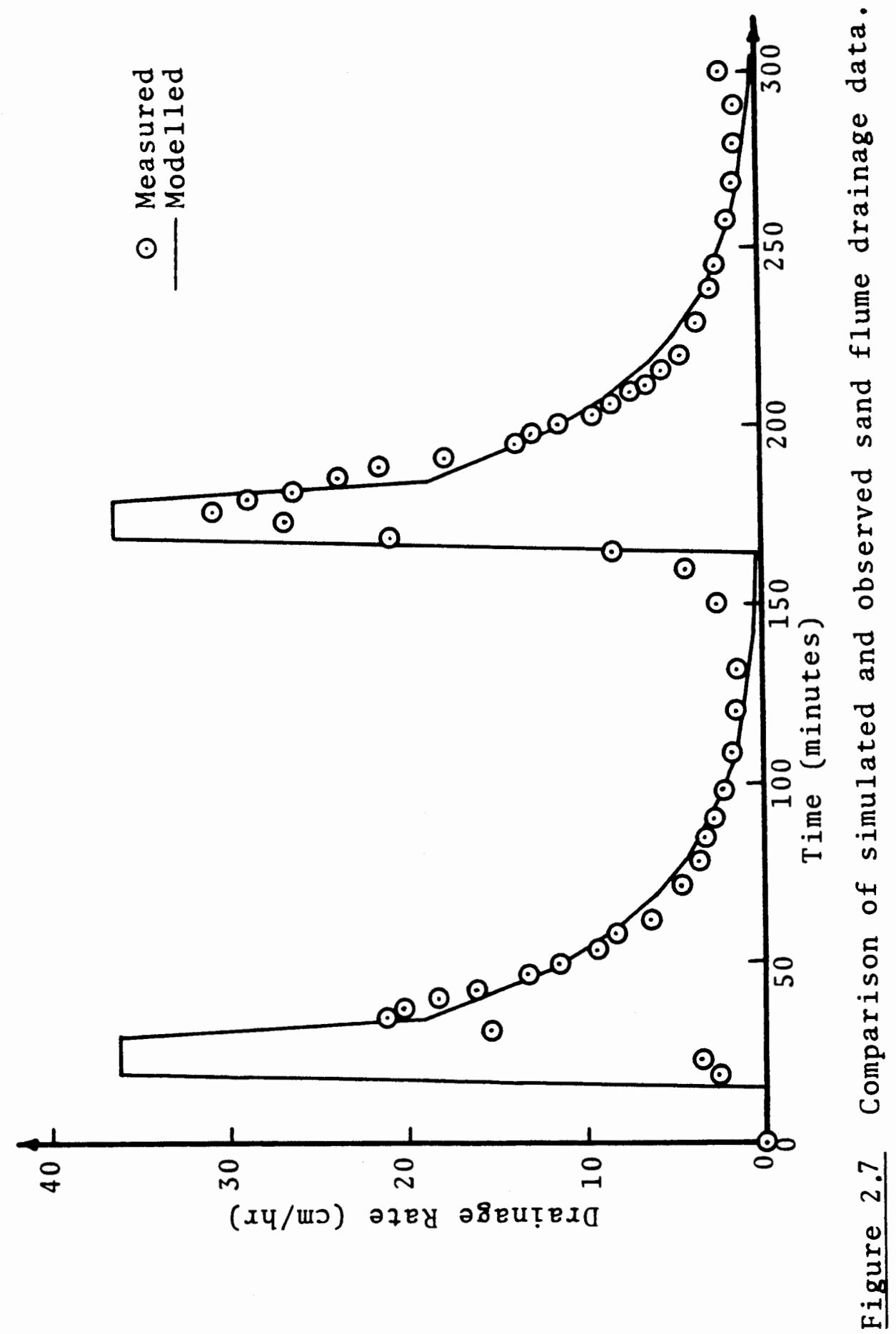


model since it is assumed that irrigation application rates will rarely exceed $K_{e}$ so infiltration may be assumed to occur at the application rate. Also, in the case of irrigation, soil moisture modelling should result in irrigations tailored to need, so little drainage will occur.

Even though drainage is not a significant part of this particular application due to the daily time scale, a comparison of drainage volumes obtained using the redistribution and drainage model presented above to volumes obtained if irrigations are assumed to instantaneously cause a uniform increase in root-zone soil moisture at the end of the day on which they occur was carried out to see if the redistribution model was necessary. The study was undertaken for sandy loam, loam, and clay loam soils each with a root-zone depth of 30 centimeters, $K_{e}$ equal to $K_{S}$, soil parameters shown in Table II, no evapotranspiration, and irrigations of .1 centimeter per hour for 12 hours, .1 centimeter per hour for 24 hours, and .2 centimeter per hour for 12 hours. In most cases the daily drainage volumes were

\section{TABLE II}

SOIL PARAMETERS FOR SANDY LOAM, LOAM, AND CLAY LOAM

$\begin{array}{lrrrr}\text { Soil Type } & \begin{array}{c}\theta_{S} \\ \text { in/in }\end{array} & \begin{array}{c}\theta \text { f } \\ \text { in/in }\end{array} & n & \begin{array}{c}K_{S} \\ \mathrm{~cm} / \mathrm{hr}\end{array} \\ \text { Sandy Loam } & .40 & .21 & 6 & 10.9 \\ \text { Loam } & .45 & .31 & 8 & 3.3 \\ \text { Clay Loam } & .49 & .21 & 10 & 1.02\end{array}$


nearly identical whether the wetting zone was modelled or not. The worst match was obtained for an application of .1 centimeter per hour for 12 hours on clay loam. In figure 2.8, the differences in adjacent shaded and open bars represent the differences in drainage volumes obtained for that case using the two methods. It is believed that the differences obtained for clay loam are due to that soil's greater violation of the negligible capillarity assumption. Any discrepancies between modelled and actual drainage would be further smoothed by routing of the resulting return flow, so the use of the lumped irrigation technique was adopted instead of the more complex redistribution equations. That reduced the number of variables which were required to be stored for each water use in the system and decreased the daily computation time required for each right.

\section{Evapotranspiration}

The Jensen-Haise equation (Saxton and McGuiness, 1982) was selected for calculating potential evapotranspiration since it requires only temperature and solar radiation. It is:

$$
E T_{p}=(.0006595)((.013889)(T-32)+.078) R_{S} 2.13
$$

where $\mathrm{ET}_{\mathrm{p}}$ is potential evapotranspiration in inches per day, $T$ is average temperature in degrees Fahrenheit, and $R_{S}$ is total solar radiation in Langleys per day. Actual evapotranspiration occurs at a rate reduced by the crop 

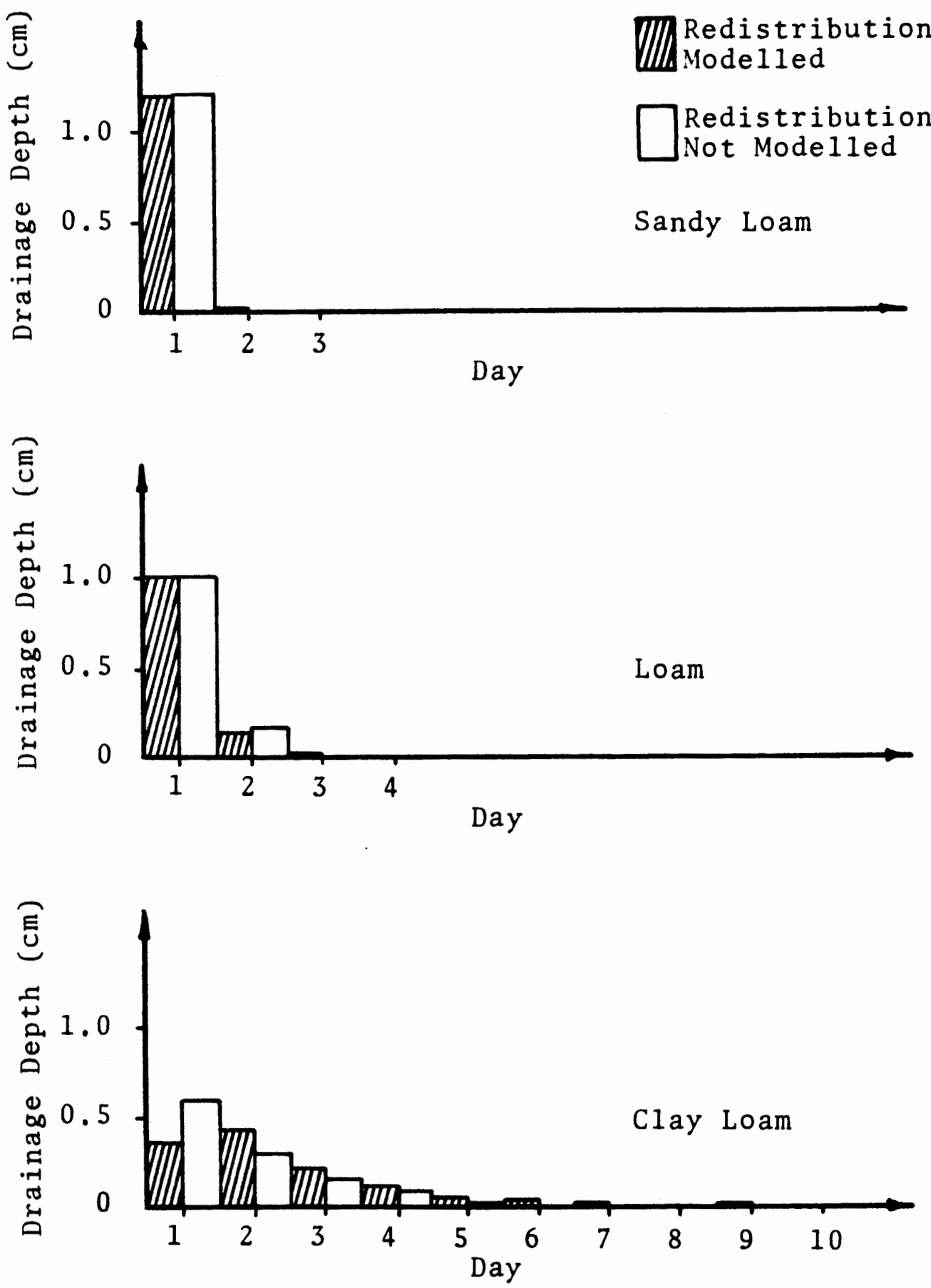

Figure 2.8 Comparison of daily drainage volumes obtained with and without modelling redistribution. Application depth is 1.2 centimeters. 
consumptive-use factor as shown by Eq. 2.9 as long as soil moisture is at or above the field capacity of the soil. Once the soil moisture drops below the field capacity, however, actual evapotranspiration is further reduced by a nonlinear function of soil moisture (Jensen, 1970) for soil moistures between $\theta_{w}$ and $\theta_{f c}$. In order to simplify the computations the function was linearized as shown in figure 2.9. A mass balance written for the root zone with no input and no drainage gives:

$$
\mathrm{d} \theta / \mathrm{dt}=-\operatorname{ET}(\theta) / D
$$

where $\operatorname{ET}(\theta)$ is the linear function shown in figure 2.9 , and ET is assumed to remove soil moisture uniformly throughout the root zone. Solving for $\theta$ as a function of time gives:

$$
\theta(t)=\theta_{w}+\left(\theta_{i}-\theta_{w}\right) \exp \left(-E T_{p} t /\left(\left(\theta_{f c}-\theta_{w}\right) D\right)\right) \quad 2.15
$$

Once again, this is a simple exponential decay of soil moisture with time.

To evaluate this expression and the method selected for calculating potential evapotranspiration, field data from the Tualatin Valley Irrigation District was simulated using Eq. 2.15 with the results shown in figures 2.10 through 2.12 for different crops. The simulations were done using soil parameters found in the Washington County soil Survey (1982). Precise locations of the fields modelled were not known, so it was necessary to use soil parameters of predominant soil types in the fields' approximate locations. Figure 2.11 shows that the selection of soil 


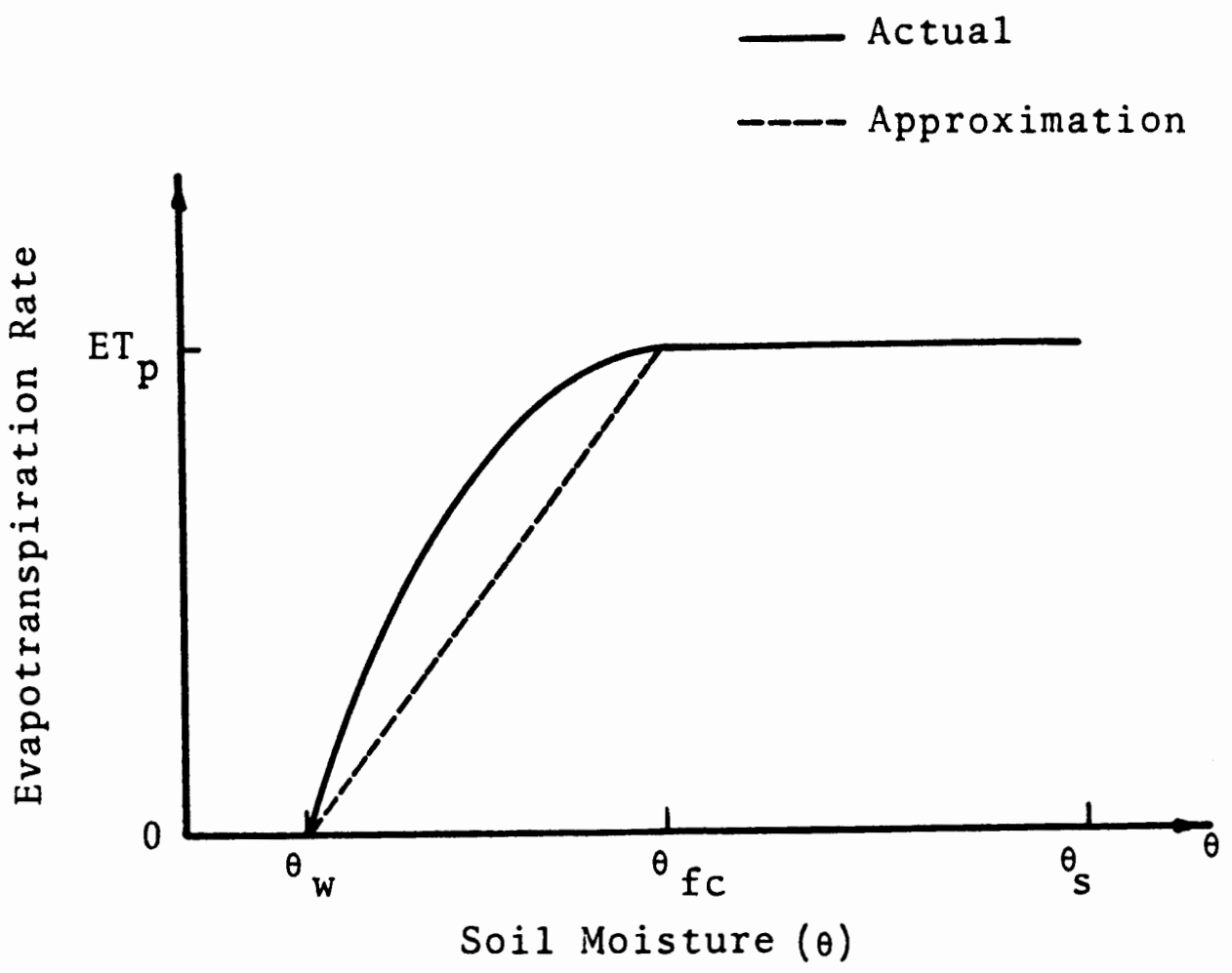

Figure 2.9 The piecewise 1inear evapotranspiration approximation. 


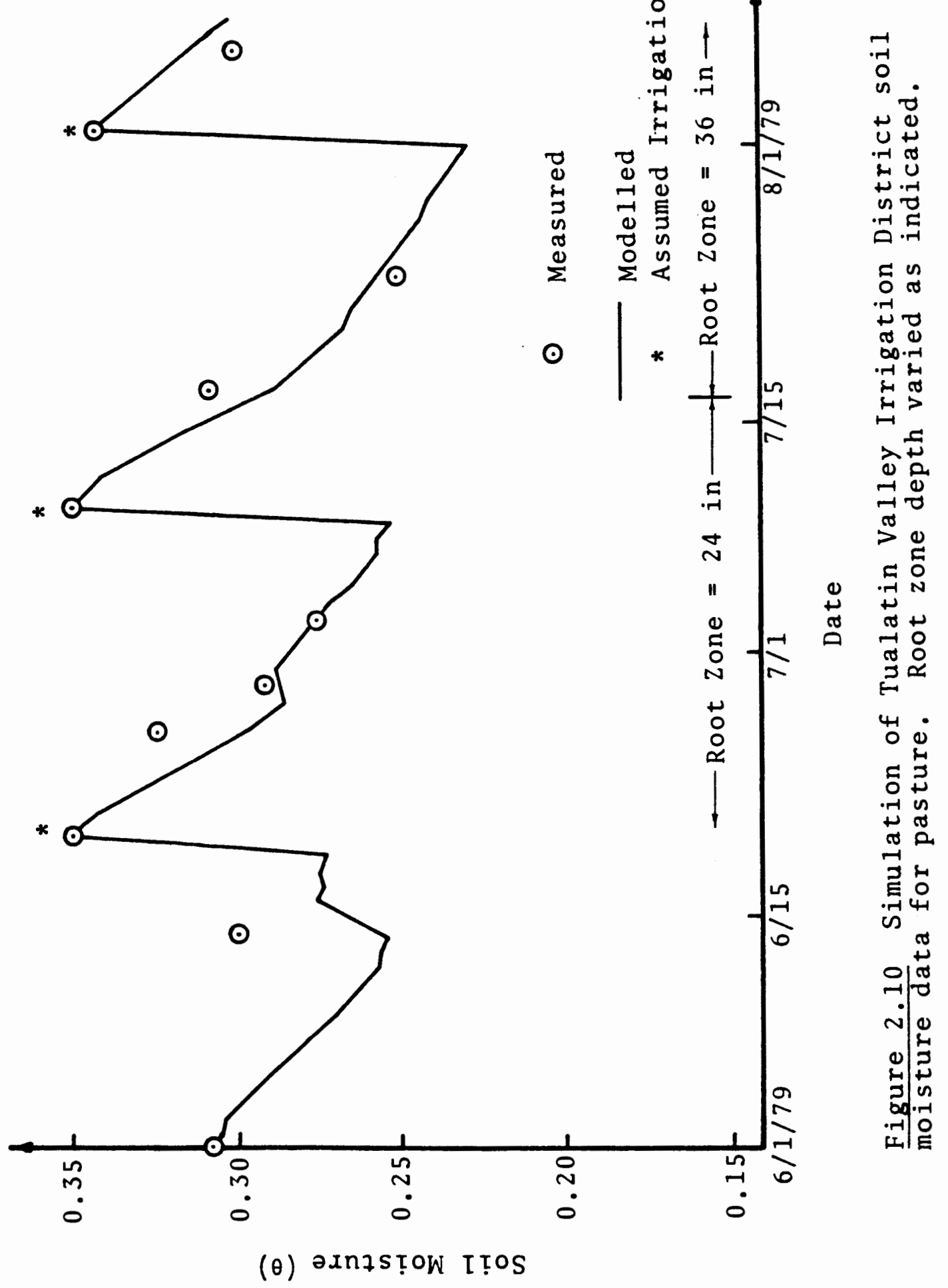




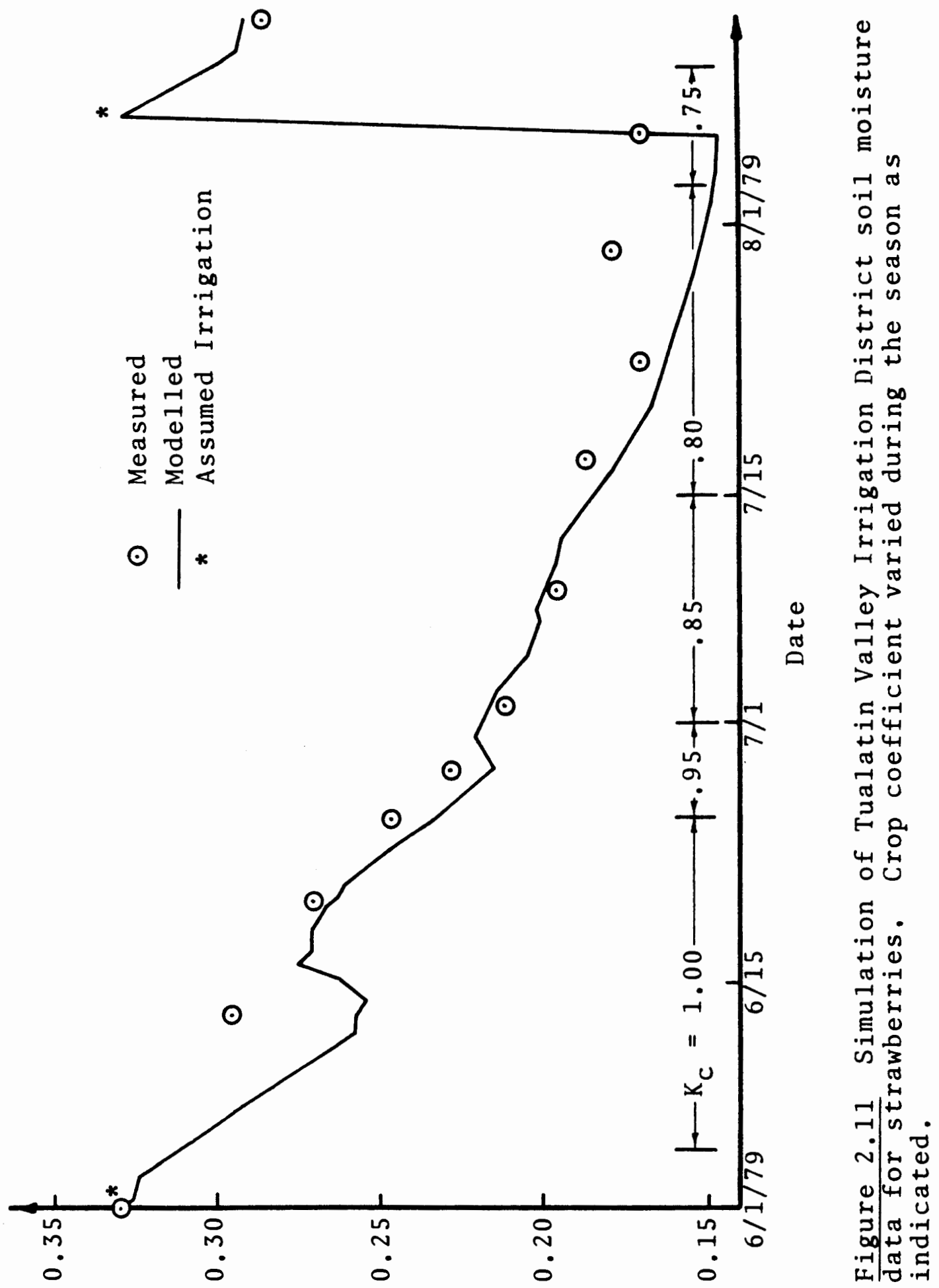

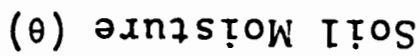




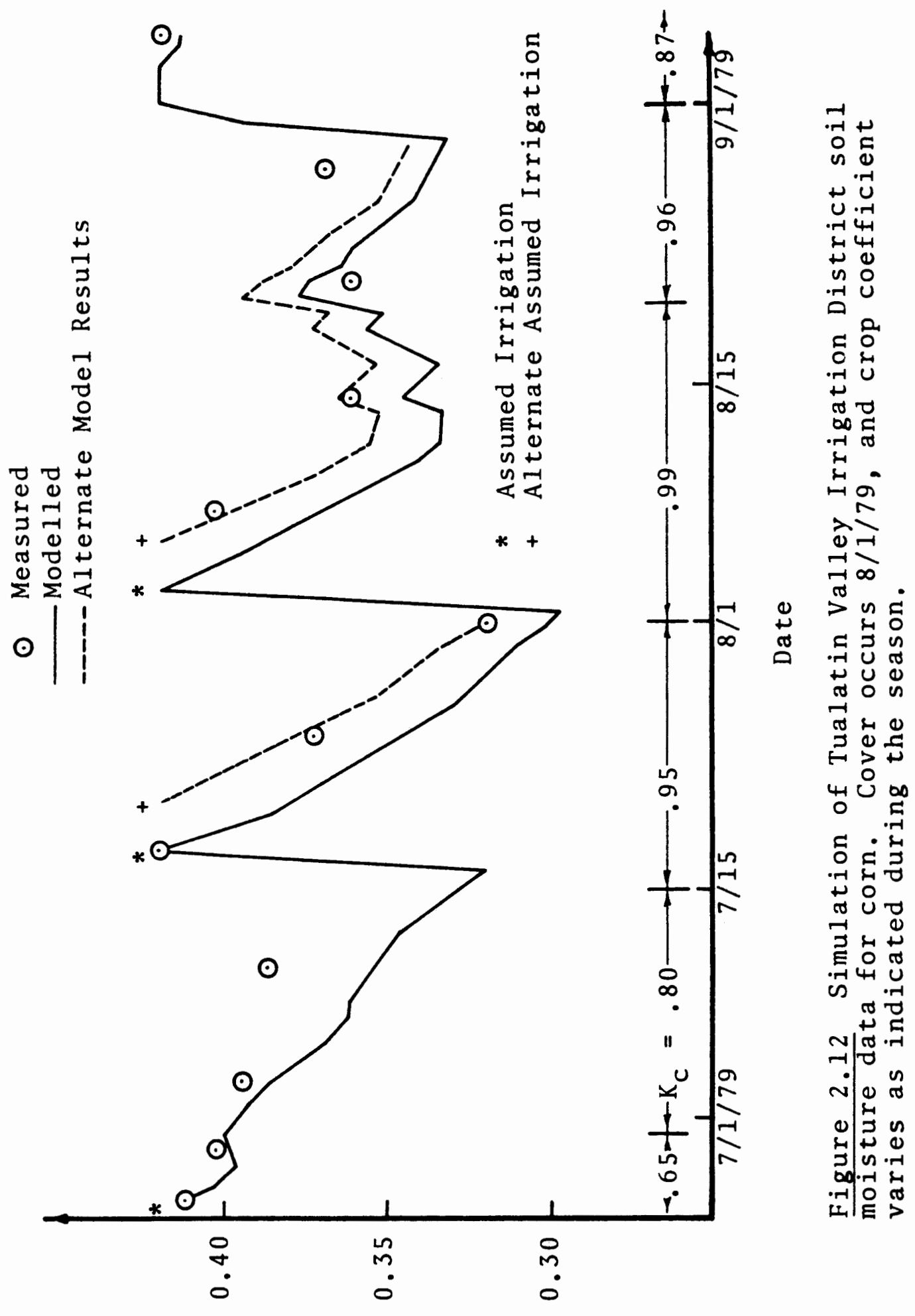

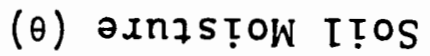


parameters may not have been adequate, since the simulated soil moisture drops below the apparent wilting point being approached by the data. It was necessary to assume that irrigations occurred as shown in the figures, but no calibration of any parameters was required. Figure 2.12 shows that the model is sensitive to the timing of actual irrigations since adjusting the assumed timing can improve the match between modelled and measured results.

The crop consumptive-use coefficient for pasture was provided by Monte McVay of the United States Bureau of Reclamation (USBR) (personal communication, 1984). Crop consumptive-use coefficients for strawberries were based on a crop curve supplied by the USBR and a cover date estimated for marion berries (similar cover characteristics as strawberries) by Esther Nelson of the North Willamette Experiment Station (personal communication, 1984). The crop coefficients for corn were based on a crop curve supplied by the USBR and another provided by Saxton and MCGuiness (1982), a planting date estimate provided by Jack Parsons of the Clackamas County Extension Office (personal communication, 1984), and a time-to-cover of 85 days after planting mentioned by Jensen and others (1973).

These simulations used temperature, precipitation, and solar radiation data from a station which was five to ten miles from the actual fields. That and the rough manner in which soil parameters were obtained may account for much of 
the model error shown in the figures. Once again, no calibration of any parameters was required.

\section{FLOW ROUTING}

Just as an accurate model of soil moisture is required to estimate demand for irrigation water, once demands are estimated it is important to have a streamflow model which provides reliable predictions of the affects of flow diversions if local water management is to be facilitated. The streamflow model selected must be complex enough to handle multiple reaches which may each receive tributary inflow and provide for water-use withdrawals, but it should be rapid when executed on a microcomputer. The selected model must meet the additional requirement of being physically based in order to aid implementation.

In this section, a review of fundamental streamflow routing concepts is given followed by a detailed development of the selected model and a presentation of that model in a manner which is convenient for the present purpose.

\section{Fundamental Equations}

The flow of water in natural channels can be described for a unit width of channel if the assumptions of one-dimensional flow, a straight channel, and gradual slope are made, by the Saint-Venant equations of continuity:

$$
\partial y / \partial t+\partial(V y) / \partial x=q_{e}-f_{e}
$$


and momentum:

$$
\mathrm{S}_{f}=\mathrm{S}_{0}-\partial \mathrm{y} / \partial \mathrm{x}-(\mathrm{V} / \mathrm{g}) \partial \mathrm{V} / \partial \mathrm{x}-(1 / \mathrm{g}) \partial \mathrm{V} / \partial t \quad 2.17
$$

(Huggins and Burney, 1982). In these equations:

$$
\begin{aligned}
& y=\text { local depth of flow } \\
& q_{e}=\begin{array}{l}
\text { lateral inflow per unit length and width of } \\
\text { channel }
\end{array} \\
& f_{e}=\begin{array}{l}
\text { lateral outflow per unit length and width of } \\
\text { channel }
\end{array} \\
& v=\text { velocity } \\
& g=\text { gravitational constant } \\
& S_{0}=\text { bed slope } \\
& S_{f}=\text { friction slope } \\
& x=\text { flow direction axis. }
\end{aligned}
$$

Unfortunately, these are nonlinear partial differential equations for which there is no known general analytical solution, so it is necessary to obtain approximate solutions by either analytically solving simplified versions of the equations, by using numerical techniques, or by a combination of these two methods. Assuming lateral outflow per unit width of channel is zero, using a wide channel assumption where:

$$
A=B y
$$

and:

$$
Q=B y V
$$

and assuming the convective and local acceleration terms in the momentum equation (third and fourth terms on the right side, respectively) cancel each other since they are usually 
approximately equal in magnitude and opposite in sign (Weinmann and Laurenson, 1979) results in the diffusive-wave simplification of the Saint-Venant Equations:

$$
\begin{gathered}
\partial Q / \partial x+\partial A / \partial t=q_{1} \\
Q=K\left(S_{f}\right) 1 / 2 \\
S_{f}=S_{0}-(1 / B) \partial A / \partial x
\end{gathered}
$$

where:

$$
\begin{aligned}
& Q=\text { total channel flow } \\
& A=\text { cross-sectional area of flow } \\
& B=\text { channel width } \\
& q_{1}=\text { lateral inflow per unit length of channel } \\
& K=\text { conveyance, defined below }
\end{aligned}
$$

and where Eq. 2.19 can represent either the Chezy or Manning flow formula. For example, if the chezy flow formula (Streeter and Wylie, 1979) is used, the conveyance, $k$, is given by:

$$
K=C A(R)^{1 / 2}
$$

where:

$$
\begin{aligned}
& C=\text { Chezy coefficient } \\
& R=\text { hydraulic radius }
\end{aligned}
$$

Further manipulation of Eq's. 2.18 through 2.20 results in the following convection-diffusion equation:

$$
\partial Q / \partial t+c \partial Q / \partial x=\left(Q /\left(2 B S_{f}\right)\right)\left(\partial^{2} Q / \partial x^{2}\right)+q_{1}
$$

where $c$ is the celerity or speed of a flood wave and the first term on the right causes diffusion in the solution (Weinmann and Laurenson, 1979). The celerity is defined as: 


$$
c=\partial Q / \partial A
$$

It may be calculated for a reference discharge based on the slope of the measured stage-discharge relation, or by dividing the measured travel time for a distinctive hydrograph component into the known distance between two gaging stations at which the component is observed.

If a finite-difference scheme is used to solve Eq. 2.22 with no diffusion or lateral inflow:

$$
\partial Q / \partial t+c \partial Q / \partial x=0
$$

the numerical solution should display convection but no diffusion. Cunge (1969) found however that numerical errors occur which produce diffusion in the solution. Since real flood waves do diffuse, Cunge equated the numerical diffusion with the physical diffusion which should occur according to Eq. 2.22 and obtained the Muskingum flow-routing equations. These had been derived much earlier based on a consideration of wedge and prism storage in open-channel flow and widely used (Linsley, Kohler, and Paulhus, 1982):

$$
S=k(x I+(1-x) Q)
$$

where $S$ is storage in the routing reach (or deviation of storage from a steady-state value) and $k$ and $x$ had previously been parameters obtained by calibration. Now $k$ and $x$ had obtained a physical basis through the equating of numerical and physical diffusion:

$$
k=\Delta x / c
$$




$$
x=(1 / 2)\left(1-Q /\left(B \Delta x c S_{f}\right)\right)
$$

where $\Delta x$ is the routing reach length and the other variables are defined above.

If the Muskingum equation (Eq. 2.25) is simplified by setting the parameter $x$ equal to zero then, in order to preserve the physical basis of the routing model, the routing reach length must be set by:

$$
\Delta x=Q /\left(B C S_{f}\right)
$$

and the resulting model is known as the linear reservoir. Eq. 2.25 simplifies to:

$$
S=k Q
$$

in which storage is a linear function of outflow only.

Since this fundamental equation is linear and since, for a reference discharge, the parameters are constant rather than a function of discharge, the powerful analytical techniques for dealing with linear differential equations can be used, but the model still has a physical basis. It is this model which was selected for use on the microcomputer and is described in detail next.

\section{The Linear Reservoir}

Conservation of mass applied to a routing reach gives:

$$
d S / d t=I-Q
$$

where $S$ is storage in the reach, I is inflow to the reach, and $Q$ is outflow from the reach. Employing Eq. 2.29 (the linear reservoir) and eliminating $S$ gives: 


$$
\mathrm{dQ} / \mathrm{dt}=(1 / \mathrm{k})(\mathrm{I}-\mathrm{Q})
$$

Equation 2.31 is a first-order linear non-homogeneous differential equation which has a solution dependent on the initial flowrate $Q_{0}$ and on the rate of inflow, $I$.

To see the effect that the initial condition $Q_{0}$ has on the solution, set the inflow equal to zero and solve for $Q$ as a function of time. The result is:

$$
Q(t)=Q_{0} \exp (-t / k)
$$

This is a simple exponential decay.

If the initial flowrate is set equal to zero and the inflow is given a constant value $I_{C}$, solving Eq. 2.31 for $Q$ as a function of time gives the response to a constant input:

$$
Q(t)=I_{c}(1-\exp (-t / k))
$$

This is an exponential approach to $I_{c}$ as might be expected. Since Eq. 2.32 is a complementary solution to the differential equation (Eq. 2.31) and Eq. 2.33 is a particular solution, the complete solution to Eq. 2.31 is the sum of the responses given by Eq.'s 2.32 and 2.33:

$$
Q(t)=Q_{0} \exp (-t / k)+I_{c}(1-\exp (-t / k))
$$

provided the input is constant. This is an example of the principle of superposition.

\section{A Cascade of Linear Reservoirs}

Typically it is necessary to use more than one routing reach since a study area will be larger than the reach 
length dictated by Eq. 2.28. Additional reaches may also be necessary if the river system has tributaries which are subject to significant water-use withdrawals, if significant tributary inflows occur, or if intermediate flow information is desired. Consider the four-reach river system sketched in figure 2.13. Equation 2.30 may be written for each of the reaches:

$$
\begin{aligned}
& \mathrm{dS}_{1} / \mathrm{dt}=\mathrm{I}_{1}-\mathrm{Q}_{1} \\
& \mathrm{dS}_{2} / \mathrm{dt}=\mathrm{I}_{2}-\mathrm{Q}_{2} \\
& \mathrm{dS}_{3} / \mathrm{dt}=\mathrm{I}_{3}-\mathrm{Q}_{3} \\
& \mathrm{dS}_{4} / \mathrm{dt}=\mathrm{I}_{4}-\mathrm{Q}_{4}
\end{aligned}
$$

where $S_{1}, I_{1}$, and $Q_{1}$ are storage, inflow, and outflow respectively of reach 1 and the other variables are similarly defined. If each reach is considered to be a linear reservoir, then the system of equations 2.35 may be re-written:

$$
\begin{aligned}
& \mathrm{dQ}_{1} / \mathrm{dt}=\left(1 / \mathrm{k}_{1}\right)\left(\mathrm{I}_{1}-\mathrm{Q}_{1}\right) \\
& \mathrm{dQ}_{2} / \mathrm{dt}=\left(1 / \mathrm{k}_{2}\right)\left(I_{2}-\mathrm{Q}_{2}\right) \\
& \mathrm{dQ}_{3} / \mathrm{dt}=\left(1 / \mathrm{k}_{3}\right)\left(I_{3}-\mathrm{Q}_{3}\right) \\
& \mathrm{dQ}_{4} / \mathrm{dt}=\left(1 / \mathrm{k}_{4}\right)\left(I_{4}-\mathrm{Q}_{4}\right)
\end{aligned}
$$

where $k_{1}, k_{2}, k_{3}$, and $k_{4}$ are the routing constants for reaches $1,2,3$, and 4 , respectively, each calculated using Eq. 2.26, a reach length based on Eq. 2.28, and physical variables from the appropriate portion of the real river system which is being modelled. 


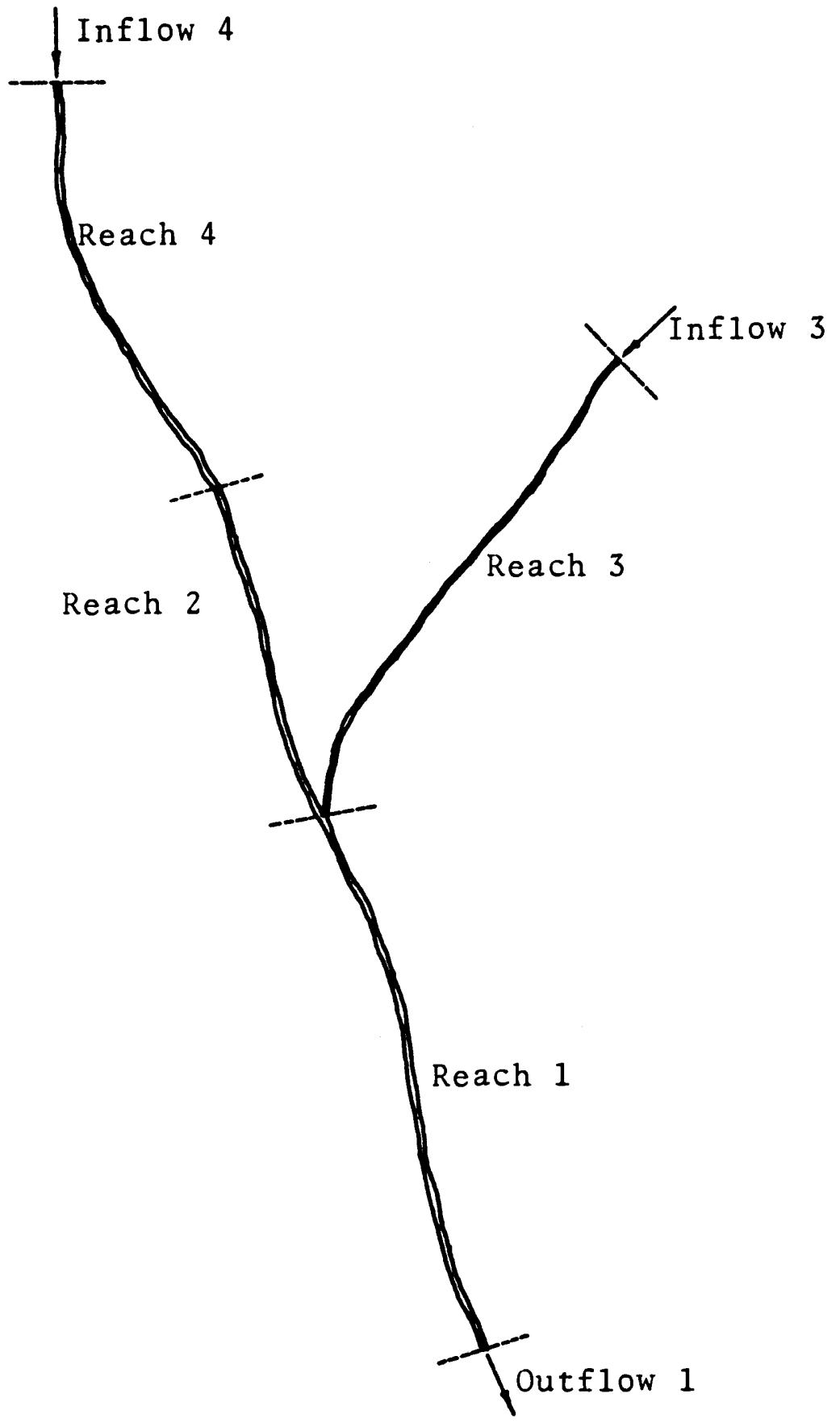

Figure 2.13 A four reach river system. 
Examination of figure 2.13 shows that the following relationships exist between the variables in Eq.'s 2.36:

$$
\begin{gathered}
Q_{4}=I_{2} \\
Q_{2}+Q_{3}=I_{1}
\end{gathered}
$$

so Eq.'s 2.36 with Eq.'s 2.37 form a system of first-order linear non-homogeneous differential equations with constant coefficients. Using Eq.'s 2.37 and re-writing Eq.'s 2.36:

$$
\begin{aligned}
\mathrm{dQ}_{1} / \mathrm{dt}=\left(1 / \mathrm{k}_{1}\right)\left(\mathrm{Q}_{2}+\mathrm{Q}_{3}-\mathrm{Q}_{1}\right) \\
\mathrm{dQ}_{2} / \mathrm{dt}=\left(1 / \mathrm{k}_{2}\right)\left(\mathrm{Q}_{4}-\mathrm{Q}_{2}\right) \\
\mathrm{dQ}_{3} / \mathrm{dt}=\left(1 / \mathrm{k}_{3}\right)\left(I_{3}-\mathrm{Q}_{3}\right) \\
\mathrm{dQ}_{4} / \mathrm{dt}=\left(1 / \mathrm{k}_{4}\right)\left(I_{4}-\mathrm{Q}_{4}\right)
\end{aligned}
$$

and then using matrix notation:

$\frac{\mathrm{d}}{\mathrm{dt}}\left[\begin{array}{l}\mathrm{Q}_{1} \\ \mathrm{Q}_{2} \\ \mathrm{Q}_{3} \\ \mathrm{Q}_{4}\end{array}\right]=\left[\begin{array}{cccc}-1 / \mathrm{k}_{1} & 1 / \mathrm{k}_{1} & 1 / \mathrm{k}_{1} & 0 \\ 0 & -1 / \mathrm{k}_{2} & 0 & 1 / \mathrm{k}_{2} \\ 0 & 0 & -1 / \mathrm{k}_{3} & 0 \\ 0 & 0 & 0 & -1 / \mathrm{k}_{4}\end{array}\right]\left[\begin{array}{c}\mathrm{Q}_{1} \\ \mathrm{Q}_{2} \\ \mathrm{Q}_{3} \\ \mathrm{Q}_{4}\end{array}\right]+\left[\begin{array}{cccc}1 / \mathrm{k}_{1} & 0 & 0 & 0 \\ 0 & 1 / \mathrm{k}_{2} & 0 & 0 \\ 0 & 0 & 1 / \mathrm{k}_{3} & 0 \\ 0 & 0 & 0 & 1 / \mathrm{k}_{4}\end{array}\right]\left[\begin{array}{c}0 \\ 0 \\ \mathrm{I}_{3} \\ \mathrm{I}_{4}\end{array}\right]$

or:

$$
d / d t(\underline{Q}(t))=\underline{A} \underline{Q}(t)+\underline{B} \underline{r}(t)
$$

This is a form which is conveniently solved using state-space techniques (e.g. Zadeh and Desoer, 1963) which are an assembly of mathematics dealing chiefly with linear systems of ordinary differential equations. 
State Space

State-space is a mathematical space which has a coordinate axis for each independent degree of freedom in the system being modelled. In the example above, there are four degrees of freedom, so the system is modelled in a four-dimensional state space. Each degree of freedom is represented by an independent state variable, so any possible configuration of the modelled system is represented by a unique point in its state space. In order to obtain intermediate flows as results of the computations, it is most convenient to assign the four flow rates $Q_{1}$, $Q_{2}, Q_{3}$, and $Q_{4}$ as the four state variables in the example. Since $Q$ and $S$ in each of the reaches are linearly related by Eq. 2.29, an alternative selection of state variables might have been $S_{1}, S_{2}, S_{3}$, and $S_{4}$. In general, any four independent variables (excluding inputs) could be selected as the state variables. The selected state variables form a state vector represented by $\underline{Q}(t)$ in the example.

The solution to Eq. 2.40 using state-space is:

$$
Q(t)=\underline{\Phi}(t) \underline{Q}(0)+\int_{0}^{t} \Phi(t-\tau) \underline{B} \underline{r}(\tau) d \tau
$$

where $\Phi(t)$ is the state-transition matrix defined below evaluated at time $t, \underline{r}(t)$ is the input or forcing-function vector, and $\tau$ is a dummy variable of integration. The first 
term on the right side of Eq. 2.41 represents the effects of the initial conditions and the second term, which is called a convolution integral, causes the solution's response to the input or forcing function.

Various techniques exist for obtaining the state-transition matrix, $\Phi(t)$. The one which is used here is:

$$
\Phi(t)=\mathcal{L}^{-1}\left((s \underline{I}-\underline{A})^{-1}\right)
$$

where $\mathcal{L}^{-1}$ is the inverse Laplace transform, I is the identity matrix of the proper size, $s$ is the transform variable, and $(s \underline{I}-\underline{A})^{-1}$ is the inverse of matrix (s $\left.\underline{I}-\underline{A}\right)$. $\Phi(t)$ is determined element-by-element using Eq. 2.42. For the example,

$$
\Phi(t)=\left[\begin{array}{llll}
\mathrm{d}_{1} & \mathrm{~d}_{2} & \mathrm{~d}_{2} & \mathrm{~d}_{3} \\
0 & \mathrm{~d}_{1} & 0 & \mathrm{~d}_{2} \\
0 & 0 & \mathrm{~d}_{1} & 0 \\
0 & 0 & 0 & \mathrm{~d}_{1}
\end{array}\right]
$$

where:

$$
\begin{aligned}
\mathrm{d}_{1} & =\mathrm{k}_{\mathrm{i}} \mathrm{IUH}_{1} \\
\mathrm{~d}_{2} & =\mathrm{kj}_{\mathrm{jUH}} \mathrm{IUH}_{2} \\
\mathrm{~d}_{3} & =\mathrm{k}_{\mathrm{k}} \mathrm{IUH}_{3}
\end{aligned}
$$

and $i$ is the number of the row in which $d_{1}, d_{2}$, or $d_{3}$ occurs. For example, the $(1,1)$ element of $\Phi(t)$ is $d_{1}$, so the appropriate $k$ to use in the first of Eq.'s 2.44 would be $k_{1}$ since the $d_{1}$ occurs in the first row of $\Phi(t)$. This is equivalent to stating that $i$ represents the reach number of 
the reach for which the response is being determined, as can be seen by examining Eq. 2.39 where each row represents the solution to the differential equation describing the reach with the number of the row. The terms $I_{1}, I_{1} H_{2}$, and $\mathrm{IUH}_{3}$ in Eq.'s 2.44 represent the instantaneous unit hydrograph for a cascade of 1,2 , or 3 unequal linear reservoirs, respectively, which are given by:

$$
\begin{aligned}
& I_{1}=\left(1 / k_{i}\right) \exp \left(-t / k_{i}\right) \\
& I_{2}= \frac{1}{k_{i} k_{j}}\left(\frac{\exp \left(-t / k_{i}\right)}{1 / k_{j}-1 / k_{i}}+\frac{\exp \left(-t / k_{j}\right)}{1 / k_{i}-1 / k_{j}}\right) \\
& I_{3}=\frac{1}{k_{i} k_{j} k_{k}} \mid \frac{\exp \left(-t / k_{i}\right)}{\left(1 / k_{j}-1 / k_{i}\right)\left(1 / k_{k}-1 / k_{i}\right)} \\
&+\frac{\exp \left(-t / k_{j}\right)}{\left(1 / k_{i}-1 / k_{j}\right)\left(1 / k_{k}-1 / k_{j}\right)} \\
&\left.+\frac{\exp \left(-t / k_{k}\right)}{\left(1 / k_{i}-1 / k_{k}\right)\left(1 / k_{j}-1 / k_{k}\right)}\right)
\end{aligned}
$$

where $\mathrm{k}_{i}$ is the reservoir constant corresponding to the reach which is represented by the particular row in the matrix equation being dealt with as was described above, $k_{j}$ is the reservoir constant for the reach just upstream of the reach being dealt with, and $k_{k}$ is the reservoir constant for the second reach upstream of the reach being dealt with. The general expression for $\mathrm{IUH}_{\mathrm{n}}$ is: 


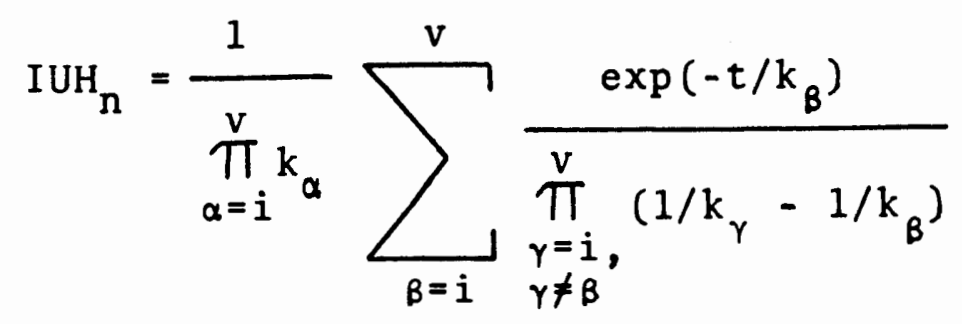

where $v$ is the number of the last reservoir upstream obtained by extending the $i, j, k, \ldots$ sequence through $n$ reservoirs. The number of linear reservoirs and the reservoir constants to be used can most easily be determined by constructing a matrix of influences, $\underline{N}$, as is shown for the example of figure 2.13 in Table III.

\section{TABLE III}

THE MATRIX OF INFLUENCES

Reach of Response Reach of Input or Initial Condition

$\begin{array}{lllll}1 & 1 & 2 & 2 & 3 \\ 2 & 0 & 1 & 0 & 2 \\ 3 & 0 & 0 & 1 & 0 \\ 4 & 0 & 0 & 0 & 1\end{array}$

The matrix of influences contains as its elements the number of linear reservoirs through which an initial condition or input in the reach of the column must flow in order to produce a response in the reach of the row. The elements in Table III correspond to the subscripts of the d's in Eq. 2.43. Once the matrix of influences is constructed, it is referred to only to determine the proper 
number of linear reservoirs to consider. The appropriate routing constants for those reservoirs must be determined by examining a map of the system such as figure 2.13.

For example, to calculate the fourth element in the first row of the state transition matrix the equation for $\mathrm{d}_{3}$ is used since an input or initial condition in reach 4 must flow through 3 reaches to appear as a response in reach 1 , according to the matrix of influences. Figure 2.13 reveals that such an input or initial condition must flow through reaches 4,2 , and 1 , so when calculating $\mathrm{IUH}_{3}, \mathrm{k}_{\mathrm{i}}$ will be $\mathrm{k}_{1}, \mathrm{k}_{\mathrm{j}}$ will be $\mathrm{k}_{2}$, and $\mathrm{k}_{\mathrm{k}}$ will be $\mathrm{k}_{4}$. In the case of a constant input between times zero and $t, \underline{r}(t)=\underline{r}$, and using a state-space result which allows the arguments of $\Phi$ and $\underline{r}$ to be exchanged, the convolution integral becomes:

$$
\int_{0}^{t} \Phi(t-\tau) \underline{B} \underline{r}(\tau) d \tau=\int_{0}^{t} \Phi(\tau) d \tau \underline{B} \underline{r}
$$

It is convenient to define a matrix called the convolution matrix to be all terms on the right side of Eq. 2.47 except the constant input $\underline{r}$ :

$$
\underline{\Lambda}(t)=\int_{0}^{t} \Phi(\tau) \mathrm{d} \tau \underline{B}
$$

The elements of $\underline{\Lambda}(t)$ are determined term-by-term by performing the integration in Eq. 2.48 and multiplying by the appropriate element of the diagonal matrix $\underline{B}$. The resulting expressions are related to the matrix of 
influences defined above. If the matrix of influences is denoted $\underline{N}$, then the elements of $\underline{\Lambda}$ are:

$$
\begin{aligned}
\text { If } \underline{N}(r, c)= & , \underline{\Lambda}(r, c)=0 \\
\text { If } \underline{N}(r, c)= & 1, \underline{\Lambda}(r, c)=1-\exp \left(-t / k_{i}\right) \\
\text { If } \underline{N}(r, c)= & 2, \underline{\Lambda}(r, c)=\frac{1 / k_{j}}{\left(1 / k_{j}-1 / k_{i}\right)}\left(1-\exp \left(-t / k_{i}\right)\right) \\
& +\frac{1 / k_{i}}{\left(1 / k_{i}-1 / k_{j}\right)}\left(1-\exp \left(-t / k_{j}\right)\right) \\
\text { If } \underline{N}(r, c)= & 3, \underline{\Lambda}(r, c)=\frac{1 /\left(k_{j} k_{k}\right)}{\left(1 / k_{j}-1 / k_{i}\right)\left(1 / k_{k}-1 / k_{i}\right)}\left(1-\exp \left(-t / k_{i}\right)\right) \\
& +\frac{1 /\left(k_{i} k_{k}\right)}{\left(1 / k_{i}-1 / k_{j}\right)\left(1 / k_{k}-1 / k_{j}\right)}\left(1-\exp \left(-t / k_{j}\right)\right) \\
& +\frac{1 /\left(k_{i} k_{j}\right)}{\left(1 / k_{i}-1 / k_{k}\right)\left(1 / k_{j}-1 / k_{k}\right)}\left(1-\exp \left(-t / k_{k}\right)\right)
\end{aligned}
$$

where $r$ and $c$ represent the row and column, respectively, of the matrices $\underline{N}$ and $\underline{\Lambda}$. If $\underline{N}(r, c)$ is greater than three, the expression for $\Lambda(r, c)$ is:

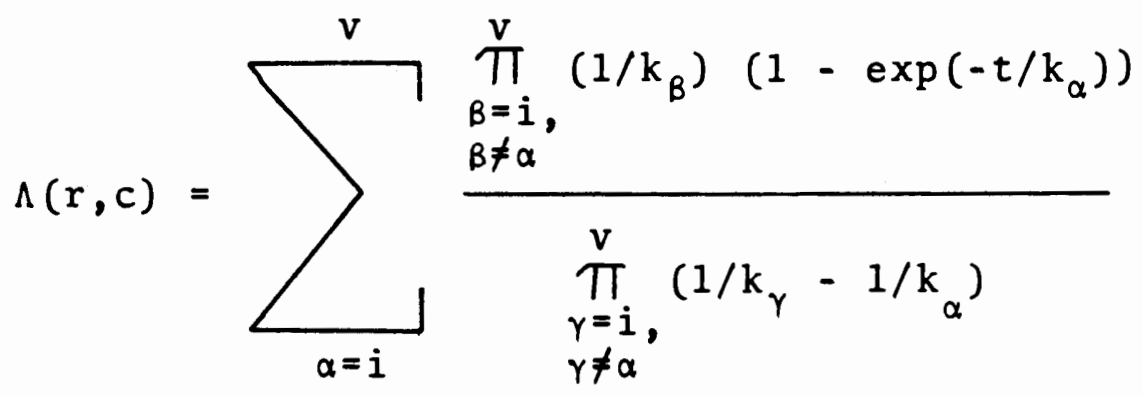

where $v$ is the number of the last reach upstream as it was in the case of the transition matrix. 
The most logical choice of the routing period $t$ in the above equations for the local water management model is one day since that will be the most likely frequency at which data about the real system will be obtained and it is possibly the frequency at which management decisions must be made during times of short water supply. Selecting a one-day routing increment requires that the main river and tributary inputs and the water-use diversions be assumed constant for a day at a time.

once the routing period is set, the matrices $\Phi(t)$ and $\Lambda(t)$ become constants rather than functions of time, and the matrix multiplication of Eq. 2.41 can be performed one line at a time provided the appropriate rows of the matrices $\Phi$ and $\Lambda$, the initial conditions $\underline{Q}(0)$, and the forcing function $\underline{r}$ are all available. The matrices $\Phi$ and $\underline{\Lambda}$, being constants, can be stored line by line in a data file and read as the matrix multiplications and addition are taking place. The initial conditions are the ending conditions from the previous day's computation, and the forcing function is the algebraic sum of main river and tributary inflows (considered positive) and water-use diversions (considered negative). The results of the computation are the flows at the end of each reach as is desired. If the initial conditions are not destroyed, the computation may quickly and easily be repeated for a variety of forcing 
functions, corresponding to a trial-and-error simulation of various distribution plans by the local water manager.

\section{Evaluation}

To evaluate the routing model, the response of the Tualatin River Basin in Northwestern Oregon to an isolated storm during September 1974 was simulated. At that time most major tributaries in the basin were gaged and irrigation diversions are assumed to have been minimal. In order to do the simulation, bed slope (to approximate friction slope) and channel width data taken from United States Geological Survey topographic quadrangle maps and a representative discharge and celerity based on published flow data from two points in the basin (United States Geological Survey, 1974) were used to calculate the required reach lengths for the linear reservoir approximation to be correct. Typical physical parameters and the resulting calculated reach lengths based on Eq. 2.28 and routing constants based on Eq. 2.26 for regions near the gaged outflow and regions near the gaged inflow are shown in Table IV.

Using these reach lengths would require approximately 65 reaches, resulting in matrices $\Phi$ and $\Lambda$ with over 4000 elements each. To avoid such large data files, the reach lengths were set so that each reach ended at a convenient 


\section{TABLE IV}

PHYSICAL PARAMETERS AND RESULTING REACH LENGTHS

FOR THE LINEAR RESERVOIR MODEL

Physical Parameter

Celerity, $c(f t / s)$

Width, B (ft)

Bed Slope, $S_{0}(f t / f t)$

Discharge, $Q$ (cfs)

Reach Length, $\Delta x(f t) \quad 7308$

Routing Constant, $k$ (s) 3990
Lower Reaches Upper Reaches

1.83

1.83

120

20

.0000997

.00063

100

4340

2370

landmark and had fairly consistent physical properties. The eight reaches shown in figure 2.14 were established in this manner. Since the reach lengths violated the linear reservoir criteria, the routing constants were recalculated using the new reach lengths and Eq. 2.26 in an attempt to preserve the physical basis of the model. The resulting reach lengths and routing constants are shown in Table $V$. 


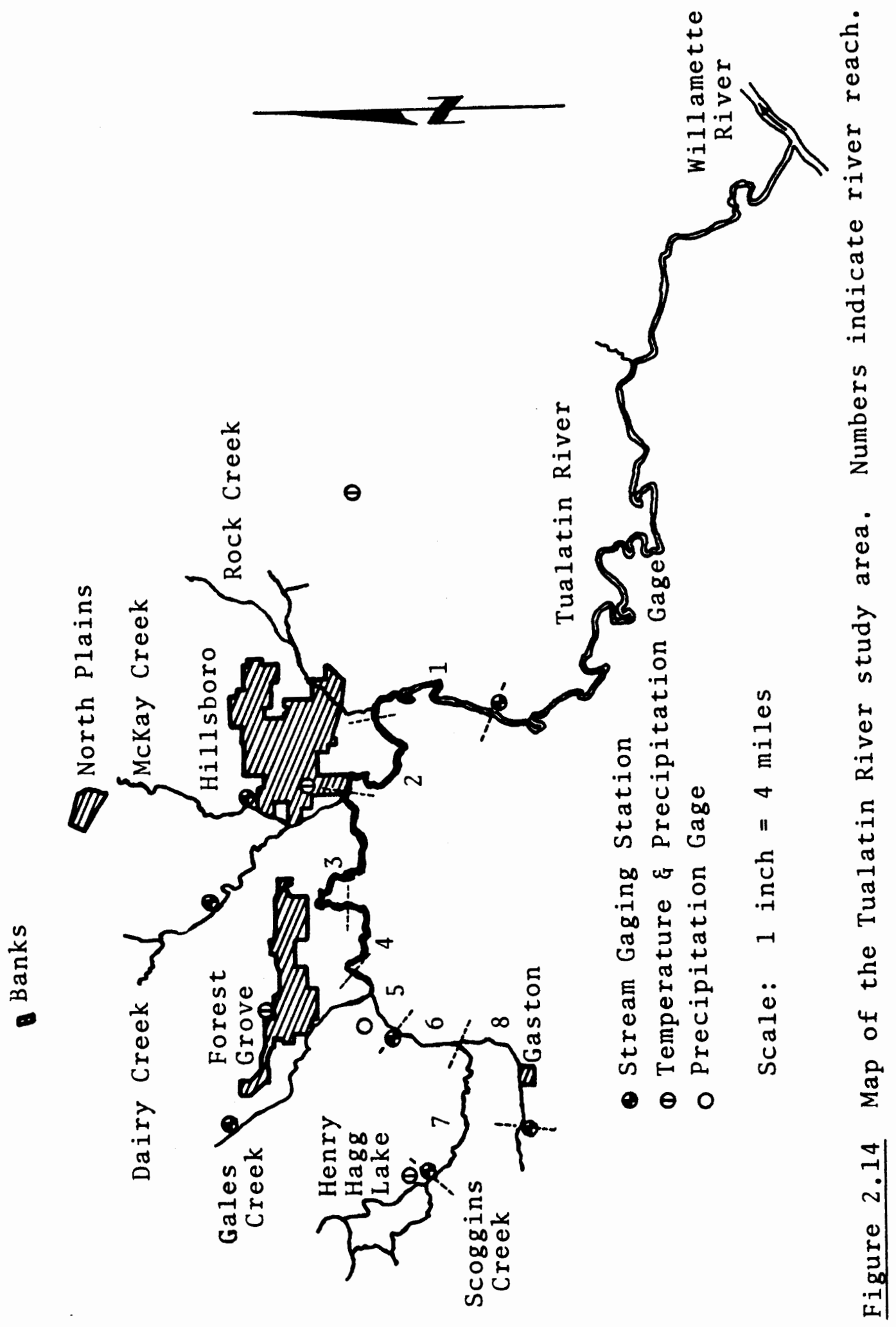


TABLE V

REACH LENGTHS AND ROUTING CONSTANTS USED IN THE TUALATIN RIVER SIMULATION

$\begin{array}{ccc}\text { Reach } & \begin{array}{c}\text { Reach Length } \\ \text { (miles) }\end{array} & \begin{array}{c}\text { Routing Constant } \\ \text { (seconds) }\end{array} \\ 1 & 5.2 & 15003 \\ 2 & 5.9 & 17022 \\ 3 & 7.1 & 20485 \\ 4 & 3.9 & 11252 \\ 5 & 3.4 & 9809 \\ 6 & 1.2 & 3462 \\ 7 & 4.8 & 13849 \\ 8 & 3.9 & 11252\end{array}$

The matrices $\underline{N}, \underline{\Phi}$, and $\underline{\Lambda}$ obtained using these reaches and routing constants are:

$$
\underline{N}=\left[\begin{array}{llllllll}
1 & 2 & 3 & 4 & 5 & 6 & 7 & 7 \\
& 1 & 2 & 3 & 4 & 5 & 6 & 6 \\
& & 1 & 2 & 3 & 4 & 5 & 5 \\
& & & 1 & 2 & 3 & 4 & 4 \\
& & & 1 & 2 & 3 & 3 \\
& & & & 1 & 2 & 2 \\
& & & & & 1 & 0 \\
& & & & & & \\
& & & & & & 1
\end{array}\right]
$$




$$
\Phi=\left[\begin{array}{rrrrrrrr}
.008 & .036 & .137 & .089 & .100 & .024 & .090 & .105 \\
& .007 & .068 & .053 & .070 & .017 & .074 & .108 \\
& & .024 & .022 & .035 & .009 & .044 & .069 \\
& & & .000 & .003 & .001 & .007 & .015 \\
& & & .000 & .000 & .001 & .004 \\
& & & & .000 & .000 & .001 \\
& & & & & .000 & .000 \\
& & & & & & & .000
\end{array}\right]
$$

$$
\Lambda=\left[\begin{array}{rrrrrrrr}
.992 & .956 & .819 & .731 & .630 & .607 & .517 & .483 \\
& .993 & .925 & .872 & .802 & .785 & .711 & .677 \\
& & .976 & .954 & .919 & .911 & .867 & .842 \\
& & & 1.00 & .997 & .996 & .990 & .982 \\
& & & 1.00 & 1.00 & .999 & .996 \\
& & & & 1.00 & 1.00 & .999 \\
& & & & & 1.00 & .000 \\
& & & & & & & 1.00
\end{array}\right]
$$

where all blank entries are zeroes.

Gaged average daily flow data for the Tualatin River near Gaston and Scoggins Creek below Henry Hagg Lake near Gaston were the major inputs for the simulation. Of the tributaries shown in figure 2.14 in the study area, Gales Creek, Dairy Creek and Mckay Creek were gaged during the simulated month, but Rock Creek was not. It was necessary to estimate the daily flow in Rock Creek by subtracting the daily gaged flows in Gales Creek, Dairy Creek, McKay Creek, 
and the Tualatin River near Dilley (gage between reaches 5 and 6) from the daily gaged flow in the Tualatin River at the Farmington Gage (the downstream end of reach 1 ). The results of the simulation are plotted in figure 2.15. Much of the error shown there can be attributed to the estimated flows in Rock Creek. Also, the measured data represent average daily flows but the simulated data are instantaneous flows.

\section{RETURN FLOW}

The Tualatin River receives little irrigation return flow according to Palmer Torvend of the Tualatin Valley Irrigation District (personal communication, 1984) due to the basin's width and gentle slopes in the area of irrigated farmland. Since the initial study area is the Tualatin River, return flow is not included as part of the model. Adequate provisions exist in the structure of the data files to allow easy incorporation of a return flow model in the future. 


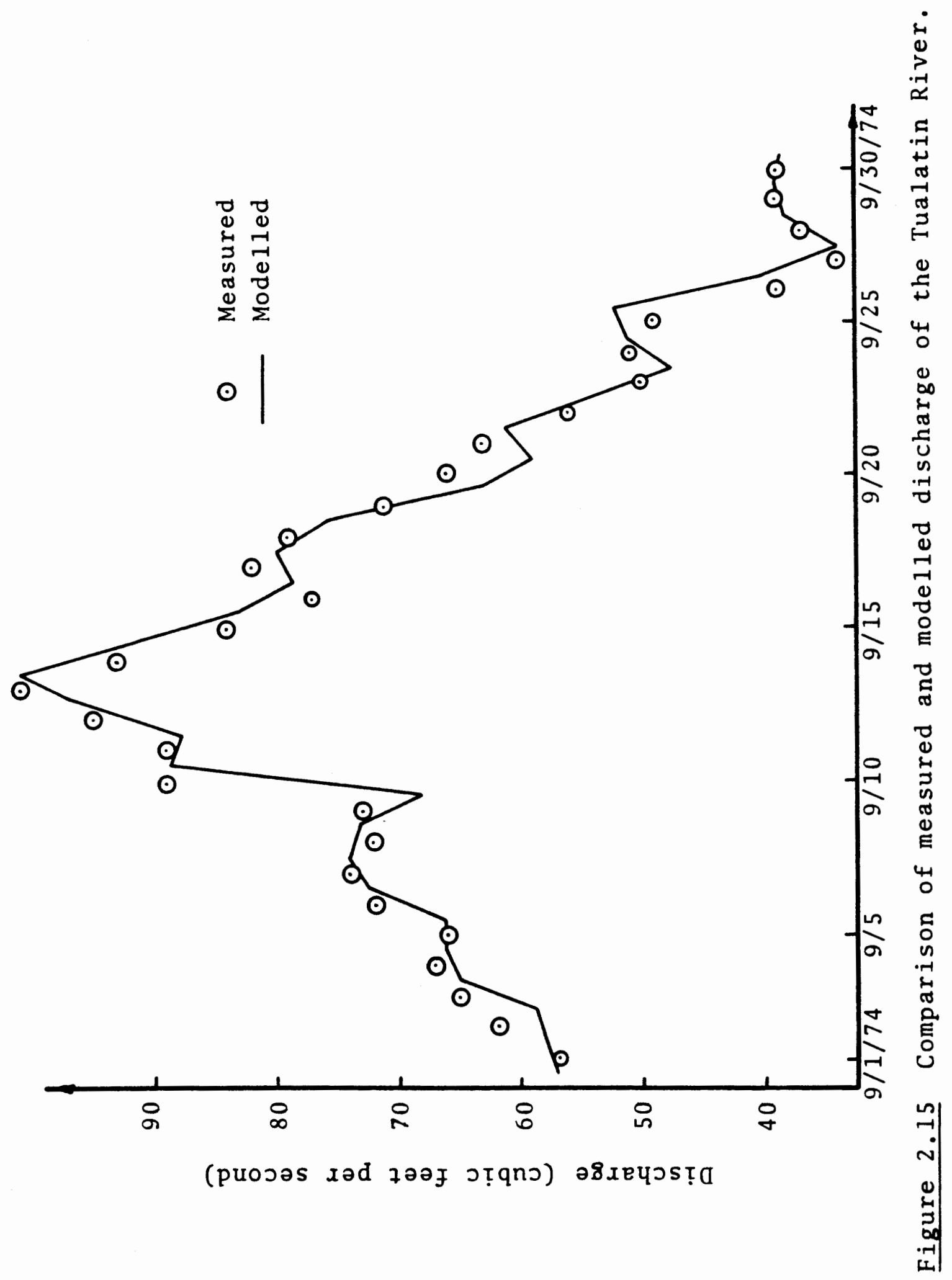




\section{CHAPTER III}

\section{THE DATA BASE}

Since simple algebraic expressions are used to model components of the hydrologic cycle, the major demand made by the decision support system on computer hardware is one of data handling. If implementation occurs on a river system which supplies water to a large number of users the data storage requirements may quickly exhaust a microcomputer's capacity, so close attention to the data requirements and data handling characteristics of the model is essential.

\section{DATA REQUIREMENTS FOR WATER MANAGEMENT}

The purpose of the Decision Support System is to perform soil moisture accounting for each user of a river system and to use the resulting estimates of water needs in a flow routing computation so that a local water manager may know the results of a proposed management scenario. The individual computations are simple enough to do by hand, but doing so for each right in a system in an iterative process would take too much time. The DSS, using the computational speed of a microcomputer, is intended to make the proposed number of calculations feasible. 
Since soil moisture computations for each irrigation use in a river system are required, it is necessary to specify the soil and crop types for each field and daily climatological data for each day of simulation. Supporting lists of parameters for each soil and crop type specified must be provided. In the case of crops, parameters may vary throughout the irrigation season.

Flow routing computations depend on the routing constant for each reach modelled and on all inflow to and diversions from the river system. The routing constants in turn depend on physical data about the river.

It is also necessary to describe the interaction of the components of the model. For example, the point of diversion of each use in terms of routing reach and the number of the reach receiving return flow from each use must be specified. Additional miscellaneous items are also required.

\section{SPECIFIC DATA REQUREMENTS}

Requirements of the DSS in its current version may conveniently be grouped as water use data, hydrologic data, flow routing data, crop and soil parameters, and miscellaneous information. Each of these data types is discussed below. 
Water Use Data

Data stored for each water use in the system is listed in Table VI.

\section{TABLE VI}

DATA STORED FOR EACH WATER USE IN THE SYSTEM

Relative Priority Number

Reach from which Water is Diverted

Reach into which Return flow occurs

Maximum Allowed Rate of Diversion

Maximum Volume of Use Allowed in the Irrigation Season

Legal Water Right Number

Legal Priority Date

Code Indicating the Type of Use

Code Indicating the Method of Irrigation

Code Indicating the Type of Crop

Code Indicating the Type of Soil

Area of the Irrigated field

Code Indicating the Climatological Zone

Cumulative Use to Date

Current Soil Moisture

A complete description of each listed item is given by Allen and Koch (1985). A brief description will be given here. 
The routing reach receiving return flow is not used in the current version of the program, but room has been provided for its specification so that the return flow component of the hydrologic cycle may be easily included in the model. The legal water right number and priority date are included for convenience of the local water manager who typically uses them in existing records. The priority number is used in place of the priority date throughout the model for programming simplicity. Each of the codes specified must be supported by a list of parameters or characteristics except the type of use code which has been included for future expansion. Currently, the model accounts for irrigation uses only. The climatological zone code is used to obtain appropriate local values of temperature and precipitation for each use from a list of climatological data which is specified as part of the hydrologic data described below.

Hydrologic Data

The model permits the establishment of up to five climatological zones depending on the number of weather stations available. For each day of simulation, a measured or estimated quantity of solar radiation which is used in all five climatological zones is required. Four air temperatures and five precipitation depths are also required (the fourth and fifth climatological zones are assumed to 
have the same air temperature). The rate of flow at up to seven gaging stations on the modelled portion of the river is specified daily. The location of each specified gage, in terms of reach number, is listed in a miscellaneous parameter file.

Flow Routing Data

Before flow routing computations can be done it is necessary to have data such as river slope and width, wave celerity, and a representative discharge for all regions of the river which are to be modelled if the linear reservoir model is to be physically based. If reaches can not be kept at the length required for the linear reservoir model to be strictly physically based, then it is necessary to know the length of the selected reaches and the wave celerity in those reaches in order to calculate a routing constant which is appropriate. These routing constants are used by the person implementing the model to calculate entries in the transition and convolution matrices based on equations presented in Chapter II. The file-editing portion of the DSS is then used to enter the convolution and transition matrices into data files for use by the routing model. The number of reaches used must be listed in the miscellaneous parameter file.

Once the model is set up, flow routing computations require daily values of main river and tributary inflows, 
proposed water use diversions, and initial flows throughout the river system. The proposed water use diversions are calculated automatically based on the manager's proposed distribution scheme and estimates of soil moisture are provided by the model. Initial flows are the results of the previous day's routing computations except that gaged flows are used by the program to replace the computed flows for reaches with gages. Main river and tributary inflows must be provided by the operator.

\section{Crop and Soil Parameters}

Each soil referred to by a soil code must have a wilting point, field capacity, and natural saturation soil moisture specified in a soil parameter file. Although it is not currently used, provision has also been made for entering the maximum relative hydraulic conductivity discussed in Chapter II so that the return flow component may be easily included.

Unlike soils, crops have parameters which may vary depending on the stage of growth of the crop. The crop parameter file has therefore been organized to allow the specification of piecewise linear functions of consumptive use coefficient, root zone depth, and critical percentage of available water requiring irrigation as a function of date for each crop code used. 
Miscellaneous Information

In addition to the data mentioned above, the efficiency of each irrigation method referred to by code is included in the miscellaneous parameter file. An additional file exists for specifying special conditions such as the irrigation of a field before the soil moisture reaches the critical soil moisture, or the lack of irrigation after the soil moisture has dropped below that value when priority is not controlling.

\section{SOURCES OF DATA}

Since the component models are physically based they rely on parameters which are physically measurable characteristics of the real system, so most required information is readily available. Implementation of the system on a basin or first time use for an irrigation season requires a large amount of descriptive information. Subsequent daily use requires additional current information.

Initial descriptive information is available from a variety of sources. Soil parameters can be obtained for each predominant soil type in the modelled basin from a Soil Conservation Service (SCS) soil survey of the county in which the basin is located. Legal water rights data including diversion location and irrigated area is available through the local state watermaster's office. The 
irrigation method and crop type for each use may require a field check or may be available in many cases from the SCS. Efficiencies corresponding to each irrigation method may also be available from the SCS or a county extension office. Descriptive information about the river can be obtained from United States Geological Survey (USGS) topographic quadrangle maps. Some information, such as the river width, may be obtained from the USGS where they maintain a stream gaging station. Otherwise, field data collection may be required. Celerity may be calculated using the slope of the rating curve for a stream gaging station, or it may be estimated using the records from two gages which are a known distance apart.

Since the model requires main river and all tributary inflows as daily inputs, it is necessary for the user to devise some means of estimating the flow in tributaries which are not gaged. This may be done using an independent hydrologic model or it may be done by establishing a staff gage and determing its rating curve. The reading of the staff gage can then be relayed by telephone by a local water user or water management employee if it is remote, or it can be obtained by the local water manager if the gage is nearby.

Additional daily input to the model includes temperature, precipitation, and solar radiation from weather stations in or near the basin and the discharges registered 
by any gaging stations in the modelled region. In some cases this information is available automatically over the telephone, but in others a manual observation and communication is required.

The local water manager is normally well aware of the sources and availability of this type of data in his or her area and should have little difficulty implementing the model. 


\section{THE DECISION SUPPORT SYSTEM}

The decision support system is a computer program written in FORTRAN 77 for use on an Apple IIe microcomputer equipped with two disk drives, a printer, an 80-column card and a monitor. Complete details of implementation and use are given by Allen and Koch (1985).

\section{PROGRAMMING PHILOSOPHY}

The program balances ease of use with memory limitations on a microcomputer. It is menu driven with clear choices including an option to exit to the previous menu where possible. Data entry which occurs in full page increments is implemented as suggested by Hromadka, Clements, and Guymon (1983) where possible. Since FORTRAN is particularly susceptible to type mismatch errors in user input, special routines are employed which allow the program to accept and decipher any kind of input (text or numerical with or without a decimal) so that errors are rejected before they cause a program crash. User input is also compared with minimum and maximum allowable values in most cases. 
Transportability has been a central concern addressed during programming. FORTRAN 77 was selected for use because it is a transportable scientific standard among computer languages. Subroutines were restricted to obtaining input through call statement lists rather than common blocks in order to make programming changes easier. The file editing routines have identical lists of call arguments so that additional editing routines which perform other functions may easily be included in a modular fashion if memory permits. The arguments passed to each file editing routine include the file name and record length of the file being edited so that only one version of each editing function had to be programmed for use on all the files. Every data file except one temporary file which the user is not expected to need access to includes a standard header used by the file editing routines to keep track of file size and the last date changes were made. Memory limitations prevented including that one file in the list of those to which the user has access.

Due to the limited memory available, an overlay feature of Apple FORTRAN 77 was used which permits a mainline to call subroutines into memory only when they are to be run. This proceedure slows program operation down slightly, but it greatly expands the size of program which may be used. Overlaying is completely transparent to the program operator. 
It is expected that this program or a revision of it will be implemented in an actual basin. The provisions mentioned should make that easier.

\section{PROGRAM ORGANIZATION}

Overall program structure is illustrated in figure 4.1. The main driver program, HDRV1, presents an opening title page, asks for the current date (for use in data editing only), and presents a menu with a choice corresponding to each of the three major program branches shown in figure 4.1. Subroutine MENU2 is a driver for file editing routines. Subroutine BWF is used to build workfiles based on edited files, and subroutine SMMAIN performs a simulation of the river and irrigation system using the workfiles and main files.

\section{File Editing Routines}

The workfile builder and system simulator obtain most of their input from permanent data files. The file editing routines allow the permanent disk files to be set up and edited quite easily.

Figure 4.2 illustrates the organization of the file editing routines. MENU2 drives subroutines for inserting, deleting, and listing records in the data files. Since the insert and delete routines can be used in combination to perform more elaborate functions such as changing and moving 


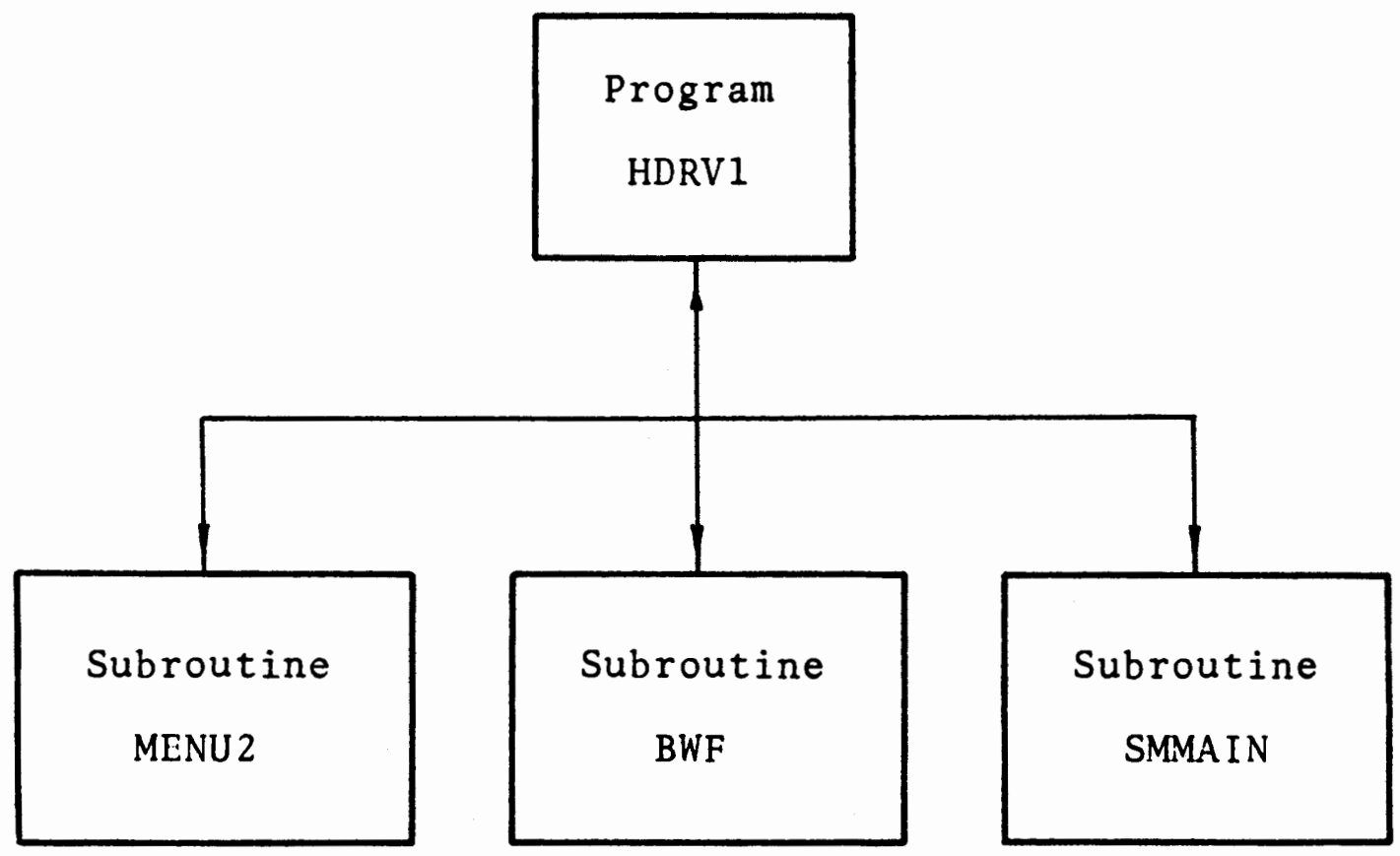

Figure 4.1 Overall program organization. 


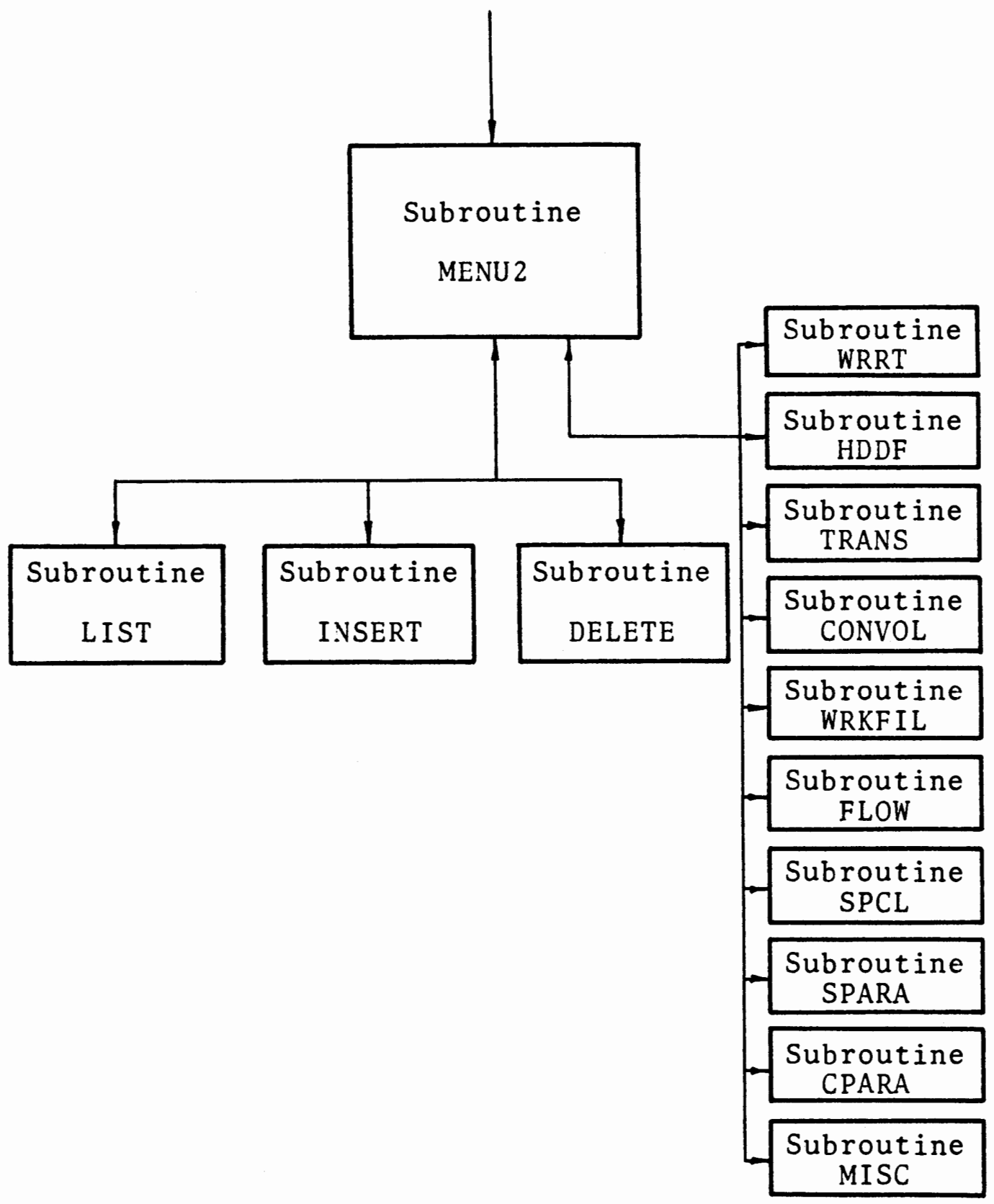

Figure 4.2 Organization of the file-editing routines. 
records, routines for those more elaborate functions were not written.

In addition to the subroutines for each of the three editing options mentioned, this branch has a subroutine corresponding to each permanent file except for the one workfile mentioned previously. Each subroutine contains information for its respective file such as file name, record length, number of fields in each record, a code indicating the type of each field, labels for the fields, and minimum and maximum permissible entries for each field. Once the operator selects a file to edit, the subroutine corresponding to that file is called to obtain editing information which is then passed to the list, insert, and delete subroutines as the operator makes the corresponding selections of editing functions. This system permits changes in the data file structure to be made relatively easily.

Figure 4.3 is an illustration of the method used by the insert routine to obtain data for one line in a data file. As was mentioned previously, input occurs in one-page increments which give a complete description of the type of input expected so that the operator will experience little difficulty in data entry. If an inappropriate or out-of-range response is given, the response is erased and the operator is given another chance to respond. 


\begin{tabular}{|c|c|c|c|}
\hline Your Response: & \multicolumn{2}{|c|}{ Acceptable Range: } & Type: \\
\hline PRIORITY NUMBER & 1 to & 999 & Integer \\
\hline DIVERSION REACH & 1 to & 19 & Integer \\
\hline RETURN REACH & 1 to & 19 & integer \\
\hline FLOW RATE ALLOUED & .00 to & 99.00 & Real \\
\hline VOLUAE ALLWD (DATE) & 0 to & 32767 & Integer \\
\hline $\begin{array}{l}\text { RIGHT NUMBER } \\
\text { PRIORITY DATE }\end{array}$ & $\begin{array}{l}\text { If to } 8 \text { char } \\
\text { If to } 8 \text { char }\end{array}$ & $\begin{array}{l}\text { ers) } \\
\text { ers) }\end{array}$ & $\begin{array}{l}\text { Character } \\
\text { Character }\end{array}$ \\
\hline TYPE OF USE CDDE & 1 to & 9 & Integer \\
\hline IRRIGATION METHOD & 1 to & 9 & Integer \\
\hline CROP TYPE CODE & 1 to & 25 & Integer \\
\hline SOIL CODE & 1 to & 25 & Integer \\
\hline ACREAGE & 1 to & 999 & Integer \\
\hline ZONE CODE & 1 to & 5 & Integer \\
\hline YEAR-DATE-USE & 0 to & 32767 & Integer \\
\hline SOIL MOISTURE & .00 to & 1.00 & Real \\
\hline
\end{tabular}

Figure 4.3 A typical page of input prompts. 
The Workfile Builder

A flowchart showing the organization and operation of the workfile builder is given in figure 4.4 . The purpose of this branch is to either build water right and flow workfiles for use by the simulation branch, or to rebuild the water right workfile for continued use by the simulation branch. It is necessary to either build or rebuild the water right workfile before each run of the simulation branch.

To build the water right workfile, the main files are read to obtain water use data, soil parameters, crop parameters, and hydrologic data for the date to be simulated. Pertinent information about each use is then written to the workfile. The water right workfile contains a record for each water use in the basin, with entries listed in Table VII. The return flow reach, maximum effective hydraulic conductivity, and soil moisture at natural saturation are not used in the current version of the model.

Rebuilding the workfile consists of recalculating those items listed in Table VII which are a function of date, based on a new date, and rewriting the workfile without changing the volume used and soil moisture for each use. Items in the workfile which are a function of date are the root zone depth, potential evapotranspiration, critical soil moisture requiring irrigation, and precipitation. 


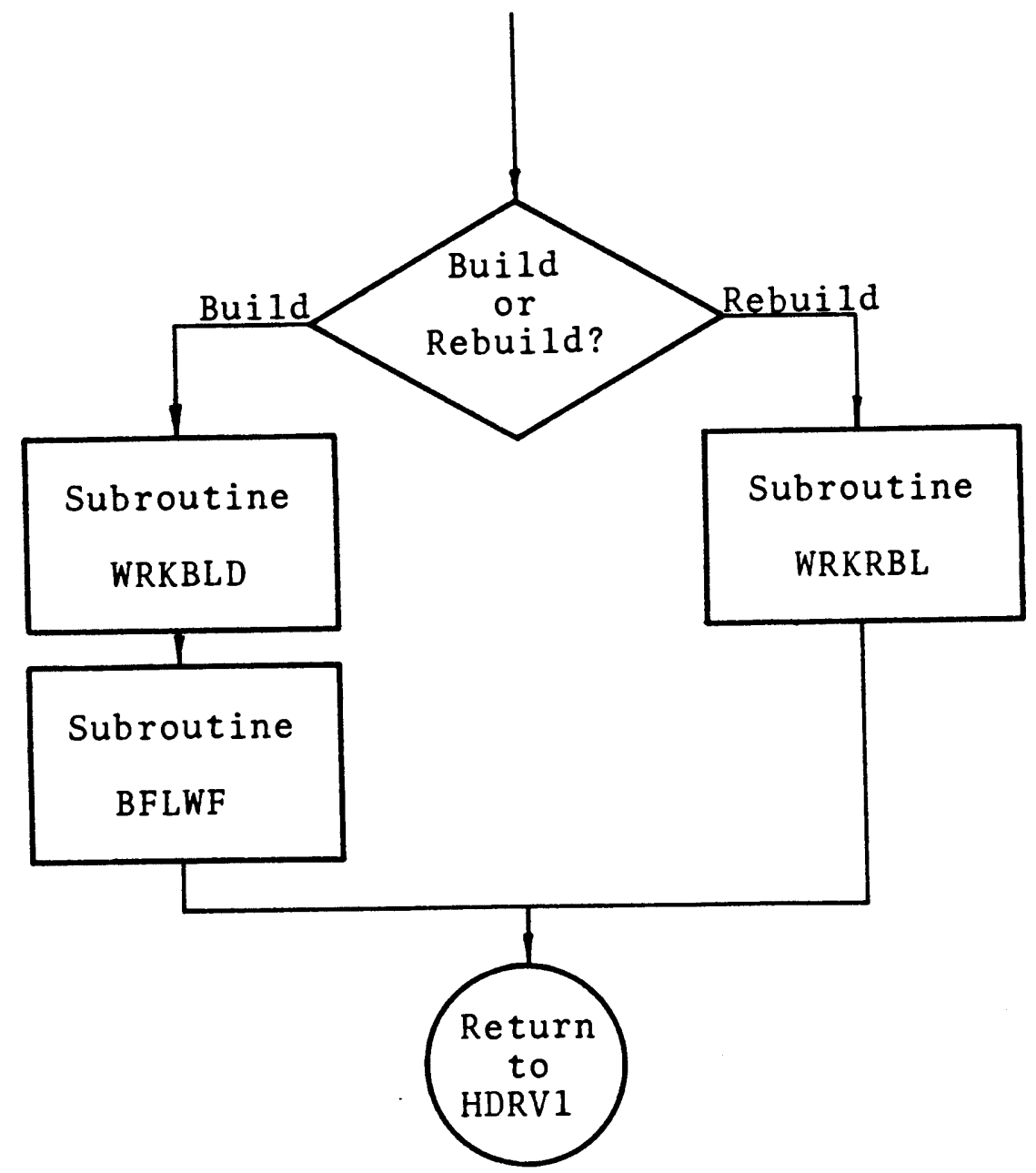

Figure 4.4 Organization of subroutine BWF. 
TABLE VII

ENTRIES IN THE WATER RIGHT WORKFILE

$$
\begin{aligned}
& \text { Priority Number } \\
& \text { Diversion Reach } \\
& \text { Return Flow Reach } \\
& \text { Flow Rate Allowed } \\
& \text { Irrigated Area }
\end{aligned}
$$

Effective Saturated Hydraulic Conductivity

Soil Moisture at Natural Saturation

Soil Moisture at the Field Capacity

Soil Moisture at the Wilting Point

Root Zone Depth

Potential Evapotranspiration

Precipitation

Critical Percent of Available Water

Irrigation Efficiency

Volume Allowed

Volume Used

Soil Moisture

The flow workfile is just a copy of the current flow rates listed in a main flow file. These are used as the initial conditions for the routing calculation in the simulation branch. Since that branch automatically updates the flow workfile with new calculated flows before an additional day is simulated, it is not necessary to rebuild 
the flow workfile as is required for the water right workfile.

System Simulator

The heart of the program is the third branch, the system simulator. The driver of this branch allows the operator to do a trial-and-error simulation of the river and irrigation system so that he or she may observe the modelled effects of various management options as is illustrated in figure 4.5 .

The subroutine SIMU mentioned in figure 4.5 performs one day of simulation in two stages. Based on the operator's cutoff priority number and special conditions, the water right workfile is read one line at a time, corresponding to one water use at a time, and a soil moisture computation is performed. The soil moisture computation consists of a decision to supply or not supply water to the field and a corresponding estimation of the new soil moisture. Throughout the soil moisture computations, irrigation water requirements are accumulated for each river reach.

Once the soil moisture computations are complete, initial conditions from the flow workfile and inputs from a permanent file are used with the water requirements accumulated during the soil moisture computations to do the second stage of the simulation, a routing computation. The 


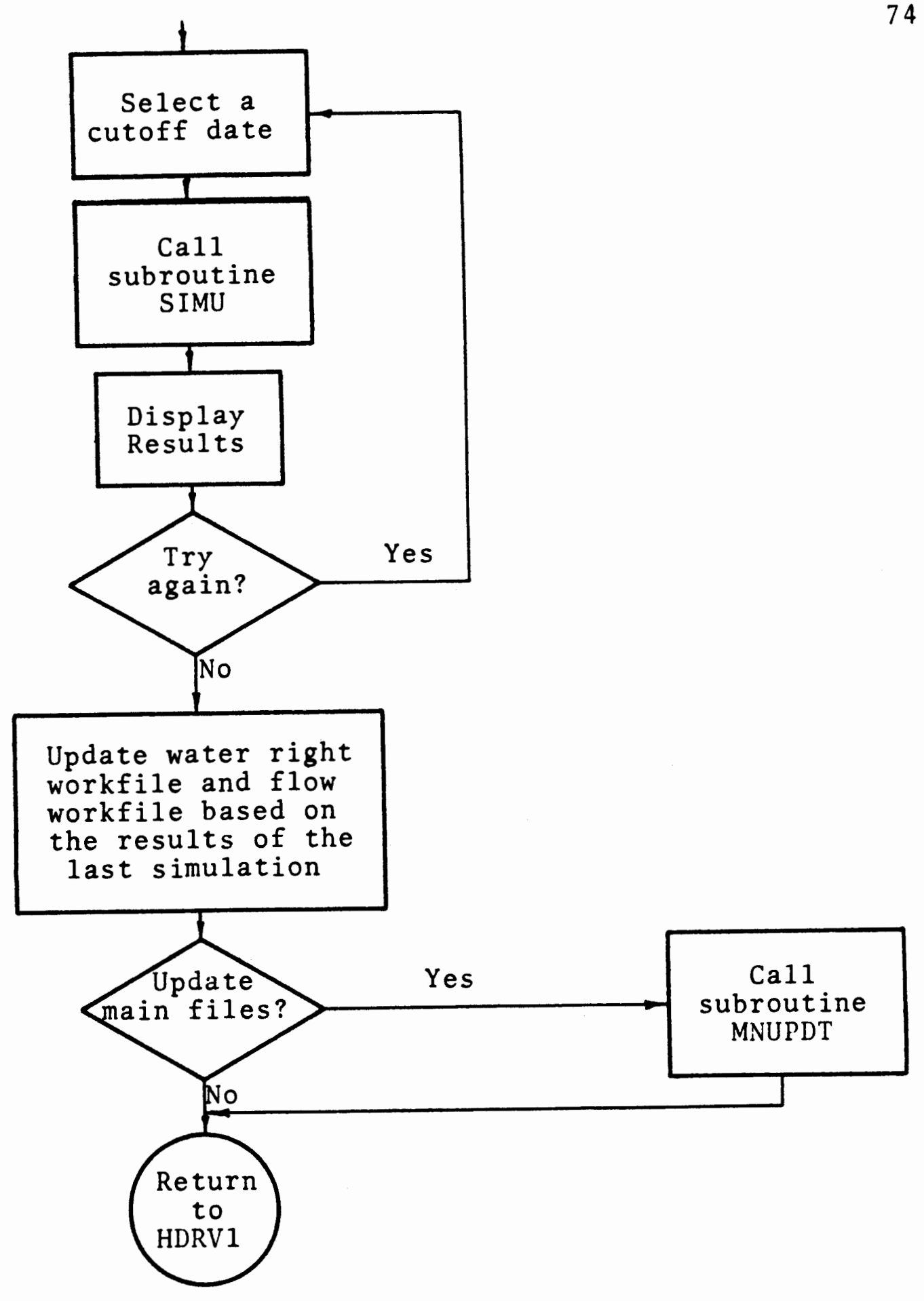

Figure 4.5 Organization of subroutine SMMAIN. 
results of that computation are stored in an array which serves a purpose identical to the purpose of the temporary water right workfile. That is, the contents of that array are used to update the flow workfile at the same time the contents of the temporary water right workfile are used to update the water right workfile.

\section{PROGRAM OPERATION}

Program operation is closely related to the organization described above. There are two types of operation. First, since it is assumed that entries in the main water right and flow files are current for the morning of the previous day, reported information about the previous day is used to update those entries for the morning of the current day in order for continuous operation to be possible. Then, given data in the main files which is correct for the morning of the current day, it is possible to use estimated climatological, hydrologic, and water use data to simulate conditions for the morning of one or more days into the future.

Complete details of program operation including an example showing the timing of construction of various files and file updates are given by Allen and Koch (1985). 


\section{CHAPTER $V$}

\section{AN APPLICATION}

Since the component models of soil moisture and flow routing have been tested independently, an application of the decision support system to a small, hypothetical river system is presented to demonstrate the interaction of those component models. Program execution time for this small system provides an indication of the feasibility of using the Decision Support System on the Apple IIe microcomputer as presently configured. Details of the step by step program operation omitted in this brief description of the application are given by Allen and Koch (1985).

Program operation centers around and is outlined by the main menu, presented in figure 5.1. As is indicated by its order of appearance, the first procedure required for use of the decision support system is the entering of river system and irrigation data into the appropriate data files which has been described in detail in the previous chapter. A map of the hypothetical river system is shown in figure 5.2. Modelled as eight reaches, the river system is supplied with water by two major and two minor tributaries. Five large irrigation water rights in three climatological zones are supplied from various reaches. As is typical of 
SHALL NE:

1. UPDATE OR ADJUST FILES

2. BUILD OR REBUILD WORKFILE FOR THE SIMULATION

3. SIMULATE A DAY

PLEASE ENTER A NUMBER ...

Figure 5.1 The main menu. 


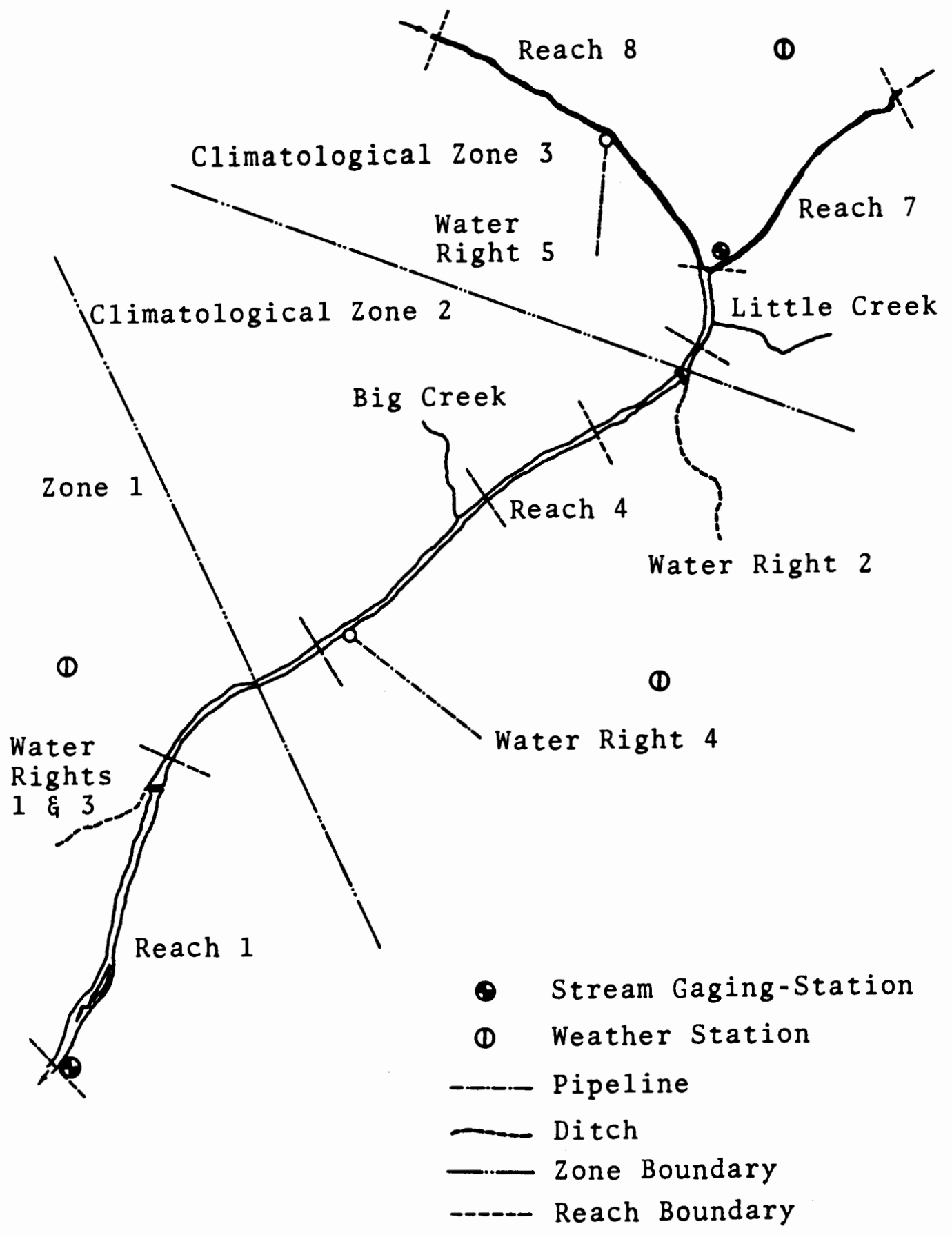

Figure 5.2 The hypothetical system. 
many real systems, the right with first priority is located near the mouth of the river. The map in figure 5.2, together with crop, soil, routing, hydrologic, and climatological data are the basis for constructing the nine required data files. Two of the data files contain the transition and convolution matrices. For simplicity, the hypothetical system was built around a river system identical to the Tualatin River, so the required data and resulting file contents are the same as was shown in Chapter II. One of the remaining seven required files contains special irrigation conditions. In the hypothetical system no special conditions were used, so that file was blank. The contents of the remaining six data files except the miscellaneous parameter file are shown in Tables VIII through XII. The miscellaneous parameter file contains the reach number of gages 1 and 2 , the irrigation efficiencies of methods 1,2 , and 3 , and the number of reaches.

Once the Decision Support System is implemented on a river system, it is only necessary to update climatological, hydrologic, and water use data for daily operation.

Assuming that data input is complete and the operator has returned to the main menu, the option to build or rebuild workfiles for the simulation is selected. For the first simulation of a day, both the flow and water right workfiles must be built. That option, or the alternative of rebuilding only the water right workfile, is selected from a 
menu presented by the workfile builder. The workfile builder performs numerous checks of consistency in the data files and presents status lines indicating progress during its operation. No additonal operator input is required. For the hypothetical example, 71 seconds elapse during building of the workfiles.

\section{TABLE VIII}

\section{WATER RIGHT DATA}

Field Label

Priority Number

Diversion Reach

Flow Rate Allowed (cfs)

Volume Allowed $\left(\times 10^{6} \mathrm{AF}\right)$

Water Right Number

Priority Date

Irrigation Method Code

Crop Type Code

Soil Type Code

Irrigated Area (Acres)

Climatological Zone

Volume Used to Date

Current Soil Moisture

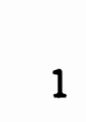

1

1

1

20

3

24032

$4 / 36$

$1 / 58$

$3 / 59$

$5 / 62$

2

1

32.8

51359

1

1

1

800

1

0

0.35

0.33

0.38

0.14

0.23 
TABLE IX

THE CLIMATOLOGICAL DATA FILE

Field Label

Date

Temperature $1\left({ }^{\circ} \mathrm{F}\right)$

Temperature $2\left({ }^{\circ} \mathrm{F}\right)$

Temperature $3\left({ }^{\circ} \mathrm{F}\right)$

Precipitation 1 (inches)

Precipitation 2 (inches)

Precipitation 3 (inches)

Solar Radiation (Langleys/day)

Flow at Gage 1 (cfs)

Flow at Gage 2 (cfs)
First Record

605

60

65

68

0

0

0

443

100

40
Second Record 606 58 55 50

0.02

0.02

0.03

407

103

37

\section{TABLE $X$}

\section{SOIL PARAMETER FILE}

$\begin{array}{ccc}\text { Record (Soil Code) } & \begin{array}{c}\text { Field Capacity } \\ (\text { in/in) }\end{array} & \begin{array}{c}\text { Wilting Point } \\ (\text { in/in) }\end{array} \\ 1 & 0.35 & 0.15 \\ 2 & 0.33 & 0.13 \\ 3 & 0.38 & 0.18 \\ 4 & 0.40 & 0.13 \\ 5 & 0.40 & 0.22\end{array}$


TABLE XI

CROP PARAMETER FILE

Crop Code Parameters Coefficient $\begin{gathered}\text { Root Zone } \\ \text { Depth } \\ \text { (inches) }\end{gathered} \begin{gathered}\text { Critical } \\ \text { Soil Moisture } \\ \text { (in/in) }\end{gathered}$

\begin{tabular}{|c|c|c|c|c|}
\hline 1 & 101 & 0.20 & 12 & 0.10 \\
\hline 1 & 601 & 0.20 & 12 & 0.10 \\
\hline 1 & 630 & 0.30 & 12 & 0.10 \\
\hline 1 & 701 & 0.30 & 12 & 0.10 \\
\hline 1 & 731 & 0.80 & 12 & 0.10 \\
\hline 1 & 801 & 0.80 & 12 & 0.10 \\
\hline 1 & 831 & 1.00 & 12 & 0.10 \\
\hline 1 & 1001 & 1.00 & 12 & 0.10 \\
\hline 1 & 1031 & 0.20 & 12 & 0.10 \\
\hline 1 & 1231 & 0.20 & 12 & 0.10 \\
\hline 2 & 101 & 0.85 & 2 & 0.15 \\
\hline 2 & 501 & 0.85 & 2 & 0.15 \\
\hline 2 & 531 & 0.85 & 6 & 0.15 \\
\hline 2 & 601 & 0.85 & 6 & 0.15 \\
\hline 2 & 630 & 0.85 & 12 & 0.15 \\
\hline 2 & 701 & 0.85 & 12 & 0.15 \\
\hline 2 & 731 & 0.85 & 24 & 0.15 \\
\hline 2 & 1231 & 0.85 & 24 & 0.15 \\
\hline 3 & 101 & 0.80 & 18 & 0.30 \\
\hline 3 & 1231 & 0.80 & 18 & 0.30 \\
\hline
\end{tabular}




\section{TABLE XII}

\section{THE FLOW FILE}

Field Label \begin{tabular}{ccc}
\multicolumn{3}{c}{ Record } \\
\multicolumn{1}{c}{1} & 2 & 4 \\
(current conditions) & (main and tributary inflow)
\end{tabular}

$\begin{array}{lrrrr}\text { Date } & 605 & 605 & 606 & 607 \\ \text { Flow 1 (cfs) } & 100 & 0 & 0 & 0 \\ \text { Flow 2 } & 102 & 0 & 0 & 0 \\ \text { Flow } 3 & 100 & 5 & 5 & 4 \\ \text { Flow } 4 & 98 & 0 & 0 & 0 \\ \text { Flow } 5 & 99 & 0 & 0 & 0 \\ \text { Flow } 6 & 100 & 1 & 2 & 1 \\ \text { Flow 7 } & 40 & 40 & 40 & 38 \\ \text { Flow } 8 & 60 & 60 & 60 & 63\end{array}$

On returning to the main menu, the option to simulate a day of operation is made. Once again, internal checks are performed to make sure that the workfiles have been built or rebuilt. If they are in order, the operator is asked for an initial estimate of the priority number of the most junior right which will receive water on the day to be simulated. For the hypothetical system shown, the operator chooses no regulation by entering 5. Approximately 56 seconds are required before the menu shown in figure 5.3 appears indicating that simulation is complete. Status lines keep the operator informed of simulation progress during that time. The operator uses menu selections to obtain the 
PLEASE MAKE A SELECTION:

1 SHITCH TO SCREEN

2 SUMMARIZE MODELLED CONDITIONS

3 PRINT A DETAILED LIST OF SOIL MOISTURES

4 EXIT THIS DISPLAY ROUTINE

PLEASE TYPE A MUMBER...

Figure 5.3 The display menu. 
reports summarizing modelled soil moisture and flow information shown in figure 5.4. As can be seen there, rights number 4 and 5 are assumed to receive water, but the others are not.

To do a second iteration, the operator exits the display menu and then chooses to select another cutoff date when given the oportunity to do so or to continue to the next menu. Priority number 3 is selected as the last right to receive water this time, as might be appropriate if a minimum flow requirement of approximately 110 cubic feet per second existed at the gage on reach number 1 , and the reports shown in figure 5.5 are obtained indicating the proposed diversion caused flows below this level. Assuming that the operator does not choose to do a third iteration since the minimum flow is not satisfied even though no irrigation is occuring, the menu shown in figure 5.6 is displayed.

Had this example been based on daily operation of a real system, the first day simulated would have been the day before the day of operation, where the day of operation is the day the program is operated. Simulation would have been based on historical data and only one iteration would have been required. Having reached the update menu shown in figure 5.6, the operator would have chosen to update the permanent files to reflect modelled conditions for the 
MODELLED CONDITIONS FOR THE MORNING OF 606

$\begin{array}{cccc}\begin{array}{c}\text { REACH } \\ \text { NO. }\end{array} & \begin{array}{c}\text { NO. OF USERS } \\ \text { NEEDING NATER }\end{array} & \begin{array}{c}\text { HATER DIVERTED } \\ \text { BY REACH }\end{array} & \text { FLOHRATE } \\ 1 & 0 & .00 & 90 \\ 2 & 0 & .00 & 86 \\ 3 & 0 & 2.00 & 82 \\ 4 & 0 & .00 & 75 \\ 5 & 0 & .00 & 75 \\ 6 & 0 & .00 & 75 \\ 7 & 0 & .00 & 40 \\ 8 & 0 & 25.71 & 34 \\ & -.-2 & -\cdots .71 & \end{array}$

MODELLED CONDITIONS FOR THE MORNING OF 606

$\begin{array}{cccc}\text { PRIORITY NUMBER } & \text { SOIL MOISTURE } & \text { VOLUME USED } & \text { IRRIGATIDN STATUS } \\ & & \text { (IN/IN) } & \text { (XI000 CU FT) } \\ & & & \\ 1 & .350 & 0 & \text { NOT IRRIGATED } \\ 2 & .327 & 0 & \text { NOT IRRIGATED } \\ 3 & .377 & 0 & \text { NOT IRRIGATED } \\ 1 & .185 & 172 & \text { IRRIGATED } \\ 3 & .400 & 2221 & \text { IRRIGATED }\end{array}$

Figure 5.4 The reports of modelled conditions. 
MODELLED CONDITIONS FOR THE MORNING OF 606

$\begin{array}{cccc}\begin{array}{c}\text { REACH } \\ \text { NO. }\end{array} & \begin{array}{c}\text { NO. OF USERS } \\ \text { MEEDING WATER }\end{array} & \begin{array}{c}\text { MATER DIVERTED } \\ \text { BY REACH }\end{array} & \text { FLOHRATE } \\ 1 & 0 & .00 & 104 \\ 2 & 0 & .00 & 105 \\ 3 & 1 & .00 & 105 \\ 4 & 0 & .00 & 101 \\ 5 & 0 & .00 & 101 \\ 6 & 0 & .00 & 101 \\ 7 & 0 & .00 & 40 \\ 8 & 1 & .00 & 60 \\ & -.0 & -00 & \end{array}$

MODELLED CONDITIONS FOR THE MORNING OF 606

PRIORITY NUMBER SOIL MOISTURE VOLUME USED IRRIGATION STATUS

$\begin{array}{cccc} & \text { (IN/IN) } & \text { (X1000 CU FT) } & \\ 1 & .350 & 0 & \text { NOT IRRIGATED } \\ 2 & .327 & 0 & \text { NOT IRRIGATED } \\ 3 & .377 & 0 & \text { NOT IRRIGATED } \\ 1 & .140 & 0 & \text { NOT IRRIGATED } \\ 3 & .230 & 0 & \text { NOT IRRIGATED }\end{array}$

Figure 5.5 Modelled conditions after the second iteration. 
WHAT SHALL HE DO NOW:

1... RETURN TO THE MAIN MENU WITHOUT UPDATING FILES

2... UPDATE MAIN MATER RIGHT AND FLON FILES

BASED ON THE SIMULATION JUST COMPLETED

NOTE: TO SIMULATE ANOTHER DAY BASED

ON THE CURRENT RESULTS IN THE MORKFILES, RETURN TO THE MAIN

MENU, REBUILD THE MORKFILE, AND THEN SIMULATE AN ADDITIONAL DAY.

PLEASE ENTER A NUMBER...

Figure 5.6 The update menu. 
beginning of the day of operation. Program control would then have returned to the main menu.

For the hypothetical example, though, the operator chooses to return directly to the main menu without updating the files. The workfile builder is then used to rebuild the workfile for an additional day of simulation so that when the simulation branch is called, it uses modelled information from the first simulation as initial conditions. In this way, the simulation into the future may be performed for as many days as estimated climatological and hydrologic data permit.

Although this simulation only considered five water rights, construction of the workfiles required 71 seconds, and simulation required 56 seconds. Each additional iteration for the same day of simulation would require an additional 56 seconds of run time, and, if additional days in the future were to be simulated, each day would require approximately 71 seconds to rebuild the workfile and several simulation iterations at approximately 56 seconds each. Since program operation centers around reading one record per water user both for building the workfiles and for simulating a day, execution time of both phases is expected to be approximately linearly related to the number of users. A real system may have from 50 to 1000 or more users, resulting in execution time from 10 to 200 minutes just to 
build a workfile, and an additional 10 to 200 minutes for each simulation iteration. 


\section{CHAPTER VI}

\section{CONCLUSIONS, SUMMARY, AND RECOMMENDATIONS}

The time required for operation of the program on a hypothetical river system with only five water users indicates that implementation of the Decision Support System on a real river system, using the existing computer configuration, may not be feasible. In addition to program execution time, a high level of cooperation from water users is required for successful operation. Currently, that level of cooperation is not likely to be available in most situations.

Increased demand and the realization by water users that soil moisture modelling can result in more efficient use of water, and thus improved profits, may make use of the DSS feasible. The availability of computer power will probably not be a limiting factor since personal computers are becoming more powerful all the time. As has been observed in an increasing number of other fields, the use of the microcomputer in local water management is expected to occur eventually. It will probably become commonplace as it has in other applications. 


\section{SUMMARY}

The development of software for use on an Apple IIe computer as a Decision Support System has been presented. The program integrates models of soil moisture and flow routing with an appropriate data base in a manner which permits a local water manager to evaluate the effects of management decisions using the model, so that decisions which maximize use of a limited supply of water may be applied to the real river and irrigation system.

A simple, physically based model of soil moisture is developed to describe redistribution, drainage and evapotranspiration based on a sharp wetting front approximation and the linearization of evapotranspiration and effective hydraulic conductivity as functions of soil moisture. For modelling redistribution the initial depth of the root zone was not selected properly, as a series of calibrations pointed out. The model's reproduction of laboratory sand flume data indicated that it worked properly. A comparison of daily drainage volumes obtained with and without modelling the redistribution process led to the decision to simplify the model further for this application by assuming that moisture input is instantaneously applied uniformly to the root zone at the end of the day on which it occurs. Simulations of soil moisture data obtained in the Tualatin Valley indicated that 
the model adequately predicted the declines which occur as a result of evapotranspiration, when the Jensen-Haise equation was used to estimate potential evapotranspiration.

A development of the linear reservoir model for flow routing based on the Saint-Venant Equations was presented. In that development, Cunge's criteria for physically basing the reach length and routing constant of the linear reservoir based on the equating of numerical and physical diffusion was pointed out. The cascade of unequal linear reservoirs was then presented in a state-space framework which was appropriate for repeated simulations and tracking of current conditions. The reach length required for the linear reservoir model to be appropriate was too short to be reasonably handled with available computer memory though, so reach lengths for the Tualatin River were set arbitrarily and the routing constant for each reach was then calculated based on the selected reach lengths in an attempt to preserve the physical basis of the model. The modelled flow during a simulated month matched measured flows closely enough to indicate that the flow routing model was adequate. Data requirements of the selected component models were then presented and discussed. It was pointed out that the DSS is very data intensive, and that a typical application may require more data than is readily available, particularly if ungaged tributaries contribute significant flows to the regulated portion of the river. 
The integration of soil moisture and flow routing component models with the data base in a program written for the Apple IIe computer resulted in the Decision Support System. The resulting system was implemented on a hypothetical river system with five water users, and an overview of program operation was given. Although the program is flexible and easy to use, it is too slow to be reasonably used as intended on the computer as presently configured. Also, in a situation with several hundred or more water users, the level of water user support required may be too great to expect until increasing demand or regulation causes users to look to conservation as a necessity.

\section{RECOMMENDATIONS}

First, some additional testing of the developed component models needs to be done. Tests of the soil moisture model on other types of soils, with more frequent field data (now available), and more closely identified parameters need to be conducted to see if the model adequately describes soil moisture for the range of crops and soils likely to be encountered in an actual implementation. Tests of the routing model using continuous or hourly data rather than daily averages would be more appropriate, especially if the Tualatin River is used, since it displays travel times on the order of days (rather than 
weeks). Also, the selection of a study basin which does not require the estimation of missing flows by mass balance is important since the mass balance computation guarantees a certain amount of success.

If additional tests of the routing model produce results which are not as close as the initial test, then a state-space formulation of the Muskingum routing method should be developed and used. This would constitute one level of refinement, and should prove adequate since it could be fully physically based with convenient routing reach lengths.

Execution time of the program could be reduced dramatically if a hard disk were used instead of floppy disks. Also, the use of an existing data base management program instead of the development of a specific one would reduce demands on memory and would probably speed program execution, even if the floppy disks are used.

Even though efforts were made to make the DSS program as flexible as possible, it is apparent that additional flexibility would be a great advantage. In particular, the method used to specify which water users do not follow the recommendations of the water budget calculations and how much water they obtain should be redone.

The DSS, if implemented, will require as input estimated climatological and hydrologic data for as many days in advance as are to be simulated. Methods for 
obtaining that data are the topic of current research by others.

Finally, as is the case with many computer applications, the success or failure of an implementation will depend heavily on the expectations of the local water manager who implements it. If that person does not want the program to work, it certainly will not. If, on the other hand, that person is interested in having the program work and is willing to adapt it as required, it can provide that manager with information which would otherwise not be available. 


\section{REFERENCES}

Allen, R. L. and R. W. Koch, 1985. User's Manual for a Decision Support System for use by Local Water Managers. To be submitted to the Oregon Water Resources Research Institute, Oregon State University, Corvallis, Oregon.

Bazaraa, Abdallah S, 1979. "Experimental/Analytical Investigation of the Recharge Rates to a Groundwater Table." Colorado State University Hydrowar Program, Fort Collins, Colorado, Interim Report for FY 1980-1981.

Cunge, J. A., 1969. "On the Subject of a Flood Propagation Computation Method (Muskingum Method)." Journal of Hydraulic Research, 7, No. 2, pp. 205-230.

Hromadka, T. V. II, J. M. Clements, and G. L. Guymon, 1983. "Guidelines for Interactive Computer Software in Water Resources Engineering." Water Resources Bulletin, 19, No. 1, pp. 91-96.

Huggins, L. F. and J. R. Burney, 1982. Surface Runoff, Storage and Routing in Hydrologic Modeling of Small Watersheds. Haan, C. T., H. P. Johnson, and D. L. Brakersiek, Ed., St. Joseph, MI: American Society of Agricultural Engineers.

Jensen, Marvin E., David C. N. Robb, and C. Eugene Franzoy, 1970. "Scheduling Irrigations Using Climate-Crop-Soil

Data." Journal of the Irrigation and Drainage Division, ASCE, 96, No. IR1, pp. 25-38.

Jensen, Marvin E., Ed, 1973. Consumptive Use of Water and Irrigation Water Requirements. Technical Committee on Irrigation Water Requirements of the Irrigation and Drainage Division of the American Society of Civil Engineers.

Koch, R. W. and R. L. Allen, 1985. "A Simple, Physically Based Model of Soil Moisture." Submitted to the Journal of Irrigation and Drainage Engineering, ASCE.

Linsley, R. K., M. A. Kohler, and J. L. Paulhus, 1982. Hydrology for Engineers, 3rd Ed., New York: McGraw-HiTl. 
Mein, Russell G. and Curtis L. Larson, 1973. "Modeling Infiltration during a Steady Rain." Water Resources Research, 9, No. 2, pp. 384-394.

Rosenbrock, H. H, 1960. "An Automatic Method for Finding the Greatest or Least Value of a Function." Computer Journal, 3, No. 3, pp. 175-184.

Saxton, K. E. and J. L. McGuiness, 1982. Evapotranspiration in Hydrologic Modeling of Small Watersheds. Haan, C.T., H.P. Johnson, and D.L. Brakersiek, Ed., St. Joseph, MI: American Society of Agricultural Engineers.

Streeter, Victor L. and E. Benjamin Wylie, 1979. Fluid Mechanics, 7 th Ed. New York: McGraw-Hill.

United States Department of Agriculture, 1982. Soil Survey of Washington County, Oregon. So il Conservation Service.

United States Geological Survey, 1974. 1974 Water Resources Data for Oregon Part 1. Surface Water Records. United States Department of the Interior.

Weinmann, Erwin $P$. and Eric M. Laurenson, 1979.

"Approximate Flood Routing Methods: A Review." Journal of the Hydraulics Division, ASCE, 105, No. HY12, pp. 1521-1536.

Zadeh, Lotfi A. and Charles A. Desoer, 1963. Linear System Theory The State Space Approach. New York: MCGraw-HiTT. 